\title{
Upper-tropospheric flow features and the Alps: An overview
}

\author{
Klaus P. Hoinka ${ }^{\mathrm{a} *}$ and Huw C. Davies ${ }^{\mathrm{b}}$ \\ a Institut für Physik der Atmosphäre, DLR, Oberpfaffenhofen, Germany \\ b Institute for Atmospheric \& Climate Science, ETH, Zürich, Switzerland
}

\begin{abstract}
One focus of the Mesoscale Alpine Programme (MAP) was the study of upper-tropospheric potential vorticity (PV) anomalies that take the form of narrow meridionally elongated troughs termed 'PV streamers'. A systematic effort was undertaken within the MAP framework to: establish a streamer climatology, develop appropriate instrumentation and undertake a measurement programme to better ascertain their structure, study both their intrinsic dynamics and their modification by the Alps, and perform model experiments to examine their significance for numerical weather prediction.

Here an overview is given of the progress made toward achieving these objectives. In particular it is shown that PV streamers translating toward the Alpine region are dynamically distinctive and constitute an identifiable precursor of and contribute seminally to heavy precipitation events on the south side of the Alps and possess rich mesoscale sub-structures that can be examined with novel water vapour absorption lidar instrumentation. It is also shown that the accurate representation of a streamer might well be a critical prerequisite for accurate quantitative prediction of mesoscale precipitation. Copyright (C) 2007 Royal Meteorological Society
\end{abstract}

KEY WORDS PV streamer; heavy precipitation; MAP

Received 1 February 2006; Revised 2 November 2006; Accepted 20 November 2006

\section{Introduction}

Southern Europe is one of the preferred locations for the occurrence of narrow meridionally elongated troughs at mid- and upper-tropospheric levels (Holopainen and Rontu, 1981; Price and Vaughan, 1992). These troughs are associated with co-aligned filaments of stratospheric air extending down to tropospheric elevations, and hence are characterized by comparatively dry and ozone-rich air with accompanying high values of potential vorticity (PV; Appenzeller and Davies, 1992). The filaments have been termed PV streamers and usually evolve from the scale-contraction of eastward-propagating large-scale waves as they approach the downstream end of the Atlantic storm track.

The study of PV streamers formed one focus of the Mesoscale Alpine Programme (MAP), and the P2 project entitled 'Incident upper-tropospheric PV anomalies' was designed explicitly to examine their structure, role and significance (Bougeault et al., 2001). The project's inclusion in the MAP stemmed primarily from the recognition that a PV streamer approaching the Alps was conceivably both a precursor and an integral feature of severe precipitation in the Alpine region.

The rudimentary basis for this streamer-precipitation linkage is two-fold. First, an upper-level trough (or equivalently a PV streamer) with its accompanying jet is conducive to ascent on its eastern fringe. This region has

\footnotetext{
* Correspondence to: Klaus P. Hoinka, Institut für Physik der Atmosphäre, Deutsches Zentrum für Luft- und Raumfahrt (DLR), Oberpfaffenhofen, D-82234-Wessling, Germany.

E-mail: Klaus.Honika@dlr.de
}

long been acknowledged to be favourable both for baroclinic development and cyclogenesis (e.g. Sutcliffe and Forsdyke, 1950) and for triggering or enhancing in situ convective activity and heavy precipitation (Smith and Younkin, 1972; Maddox et al., 1979). Second, episodes of Alpine heavy precipitation with values that can exceed $200 \mathrm{~mm} \mathrm{~d}^{-1}$ on the south side (Frei and Schär, 1998) are often accompanied by a moisture-laden low-level southerly air stream impinging upon the Alpine chain, and a suitably aligned upper-level PV streamer would contribute to the evolution and strength of such a flow.

There are other examples in this general geographical area of heavy precipitation accompanying an incident PV streamer. The major phenomenon of Alpine lee cyclogenesis, a key focus of the earlier ALPEX field programme (Kuettner, 1986), is usually characterized by the presence of a PV streamer that cuts off to the south of the Alps (e.g. over the Gulf of Genoa) to form a cold-core cyclone, and the resulting cyclone tends to propagate eastwards depositing considerable precipitation along its track over the eastern part of the Alps, the Dinaric Alps, and the Apennines. A recent example was the 20-23 August 2005 event that resulted in major flooding in southern Germany, Switzerland, and central and eastern Austria. Likewise, a PV streamer often accompanies rainstorms in Israel (Krichnak et al., 2004), and such a streamer was also a feature prior to and during the devastating Algerian flood of autumn 2001 (Thomas et al., 2003; Tripoli et al., 2005).

It is noteworthy that the PV streamer project had both a distinctive and an integrative contribution within MAP. 
On the one hand it was the only component concerned explicitly with a free-atmosphere feature not dominated by orographic effects, whereas on the other hand it bore a strong link to the other projects since the presence of a PV streamer formed the synoptic backcloth for the phenomena considered in those projects. Indeed the passage of a streamer over the Alpine chain with its characteristic upper-level wind change from a southerly to northerly jet-flow can be, and often is, accompanied sequentially by: heavy precipitation events and flooding on the Alpine south side (P1 and P3), southerly gap flow through Alpine passes (P4), föhn on the Alpine north side (P5) and gravity waves over the Alpine ridge (P6) and, finally, with the onset of the northerly flow regime, the occurrence of low-level PV banners (P7) extending southwards from fine-scale features of the Alpine topography. (The notation P1-P7 refers to the numbered MAP projects; Volkert and Gutermann, 2007.)

The special character of the PV streamer subprogramme (P2) is further highlighted by comparison of its goals with those of the heavy precipitation subprogramme (P1). The latter focused on the in situ cloud microphysics and meso-scale flow dynamics, and sought to quantify the contribution of orographic effects for quantitative precipitation forecasting (QPF). In contrast, P2 was concerned with the synoptic and sub-synoptic dynamics of the incident streamer aloft, and thereby on the significance and contribution of the incident synopticscale flow to the mesoscale QPF. Co-consideration of P1 and P2 studies can shed light on the role and relative importance of cloud microphysical and mesoscale dynamical effects (e.g. orography) versus those of the synoptic-scale environment.

In the light of the foregoing, the field component of the P2 project was designed to examine the influence of streamers upon, and their interaction with, both weather and clear-air flow systems in the Alpine region. The specific objectives were: to determine the synoptic climatology (including the spatial pattern, frequency and variability of the PV streamers), to develop appropriate instrumentation to better ascertain their three-dimensional structure, to study both their intrinsic dynamics and their modification by the Alps, and to perform model experiments to examine their significance for numerical weather prediction (NWP).

Here we record the progress made during MAP toward achieving these aims and give particular attention to the MAP field phase in 1999. The paper overviews sequentially: general characteristics and significance of streamers (Section 2), the climatology of their occurrence and linkage to precipitaion (Section 3), specific aspects of the field phase including a discussion of the performance and utility of the new instrumentation - the French STradar network and the German water vapour differential absorption lidar (DIAL) system of DLR - to detail the cross-sectional fine-scale structure of a streamer (Sections 4-6), consideration of orographic and cloud diabatic effects (Section 7), and implications for NWP (Section 8).

\section{Streamer characteristics and significance: General considerations}

An archetypical example of a streamer advancing towards the Alpine region is provided in Figure 1. On the displayed $320 \mathrm{~K}$ isentropic surface, it takes the form of an elongated PV anomaly that retains a quasi-meridional orientation whilst extending equatorwards with time and translating comparatively slowly eastwards. Its occurrence was accompanied by heavy precipitation on the southern slopes of the Alps.

The streamer is associated with strong southerly/ northerly jet flow on its eastern/western fringes, and this flow pattern is also evident in the lower troposphere, albeit with a significantly weaker amplitude. Also the isentropes well up beneath the streamer to form a cold pool of reduced static stability. These signatures are in accord with the PV perspective of the balanced atmospheric flow, and moreover the streamer's elliptical shape contributes to the enhanced strength of the jet flow on its lateral fringes.

Central to the streamer's physical significance is that all the forementioned signatures are conducive to the occurrence of a heavy precipitation event on the Alpine south side (Massacand et al., 1998). In particular, the streamer can serve to: strengthen the southerly flow component toward the Alps, reduce the static stability and indeed destabilize the atmosphere to moist convection (Juckes and Smith, 2000), and provide ascent on the streamer's forward flank that can trigger or enhance (cf. Griffiths et al., 2000) and possibly sustain the convection for a prolonged period on the south side. In effect the movement of the streamer towards the Alps constitutes a dynamical precursor of the precipitation event, and its arrival at and sojourn over the immediate western vicinity of the Alps can promote and sustain the preciptation event itself.

Four major events of heavy precipitation occurred on the Alpine south side during the preparatory phase of MAP, and each was accompanied by a large-amplitude, meridionally aligned, and slowly eastward-translating PV streamer (Massacand et al., 1998). These events, named in accord with the accompanying region that experienced intense flooding, were:

'Vaison-La-Romaine', 22 Sep. 1992; *300 mm (24 h) ${ }^{-1}$; 'Brig', 23 Sep. 1993; *220 mm (24 h) ${ }^{-1}$;

'Piedmont', 5 Nov. 1994; *250 mm (24 h) ${ }^{-1}$;

'South Ticino', 13 Sep. 1995; *120 mm (6 h) ${ }^{-1}$;

( ${ }^{*}$ denotes the observed maximum rain rate).

The PV structure of each event at approximately the time of maximum precipitation, as captured in the analyses of the European Centre for Medium-Range Weather Forecasts (ECMWF), is portrayed in Figure 2(a)-(d). The overall similarity is evident with the equatorward tip of the streamers located between the Pyrenees and North Africa, and their stem centred between the Bay of Biscay and western France. An indication of the strength of 
(a)

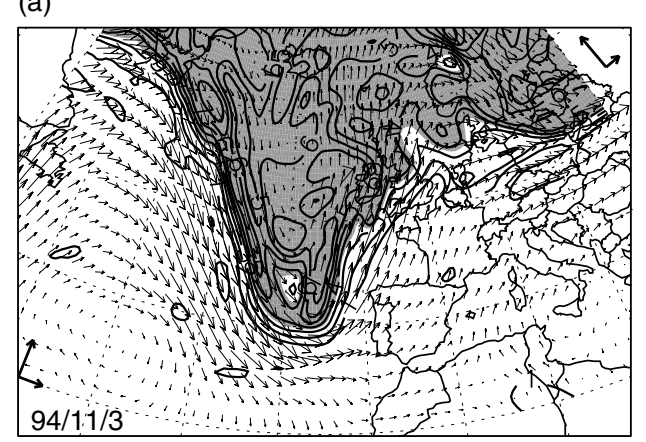

(c)

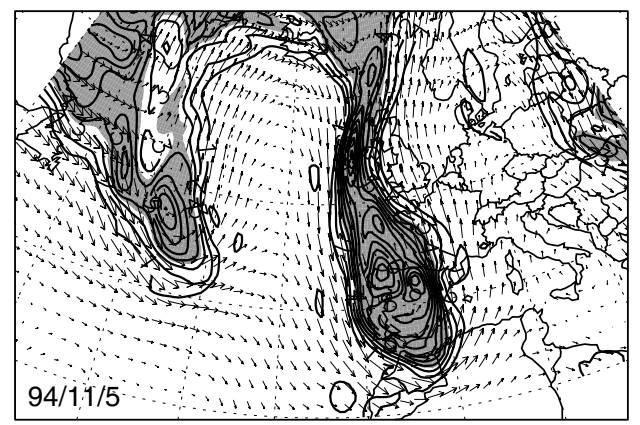

(b)

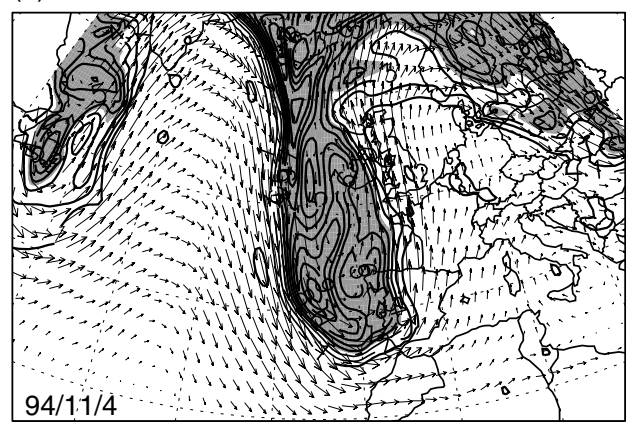

(d)

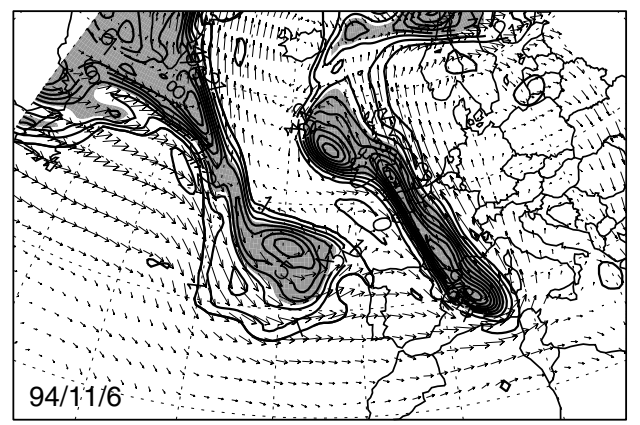

Figure 1. ECMWF analyses of wind and PV on the $\theta=320 \mathrm{~K}$ surface for 00 UTC between 3 and 6 November 1994 (Piedmont event). The PV contour interval is $1 \mathrm{pvu}$ and the shaded areas indicate regions with $\mathrm{PV}>3.5 \mathrm{pvu}$ (potential vorticity unit $=10^{-6} \mathrm{~K} \mathrm{~m}^{2} \mathrm{~kg}^{-1} \mathrm{~s}^{-1}$ ). The wind vectors are drawn in relation to the grid size. In the applied stereographic projection, the meridional grid size remains constant with latitude, but the zonal length decreases with increasing latitude. Thus it would be necessary to define the scale for each latitude. In (a) the wind vector scales are given for the southerly and northerly limits of the area considered. The displayed arrows correspond to $50 \mathrm{~m} \mathrm{~s}^{-1}$ and are correct at latitude $30^{\circ} \mathrm{N}$ (lower left corner) and $55^{\circ} \mathrm{N}$ (upper right).

the flow circumnavigating the streamers at about $200 \mathrm{hPa}$ is provided in Figure 2(e)-(h), and the corresponding low-level flow in Figure 2(i)-(1). The panels suggest that, even in the comparatively coarse ECMWF analyses (data pertain to the model version T159L60 used for ERA-40, the 45-year ECMWF reanalyses), the low-level flow is enhanced astride the streamer although its signal is obscured somewhat by orographic and diabatic influences. Note that, of the four events discussed, only the South Ticino case exhibited features akin to lee cyclogenesis, and (except for that case) the extreme precipitation was confined to the Alpine region itself.

Each event was also characterized by two particularly salient features. First is the combination of the slow eastward translation of the streamer aloft and the quasi-conservation of its geometric form. The dynamics accompanying this comparatively slow flow evolution involve a subtle interplay between the self-dynamics of the streamer and the influence of the ambient flow. The former would include an anticlockwise rotation of the streamer and also its possible break-up into a vortex train arising from a pseudo-barotropic instability, whilst the latter would include the influence of the latitudinal shear and deformation of the large-scale flow which can alter the streamer's rotation and concomitantly influence its elongation/ellipticity and lateral scale and thereby its likelihood to break up into vortices. Numerical simulations (Fehlmann, 1997; Morgenstern and Davies, 1999) indicate that, for the Alpine region and its vicinity, both the characteristic form and amplitude of streamers associated with high precipitation events and the strength and structure of the ambient flow is such that streamers can retain their shape, orientation and approximate location for a significant time period ( $\approx 1-2$ days).

The second feature is the significant and sustained moisture flux toward the Alpine ridge below ridge height. An indication of the moisture origin gained from 72-hour backward trajectories from the peak precipitation time (Massacand et al., 1998) places the source in the Mediterranean with parcel trajectories undergoing a three-phase evolution: a low-level ( $\sim 800 \mathrm{hPa})$ confluent and slow northward track whilst acquiring specific humidity values of $\sim 9 \mathrm{~g} \mathrm{~kg}^{-1}$, a rapid northward movement to the southern Alpine slopes, and thereafter sharp ascent and saturation. The rapid translation is consistent with an increasing influence of the upper-level anomaly as it advects over the Mediterranean.

\section{Climatology}

Cursory climatologies compiled in the preliminary phase of MAP indicated that about 15 events of 'moderate to heavy' precipitation over southern Switzerland during the 1993-1996 period inclusive were accompanied by PV streamers (Massacand et al., 1998), and that on average for the 1989-1998 period there were streamers directly over the Alps for 3.3 days per year with a minimum of 1 and a maximum of 9 (Steinacker, 2000). In this 
(a)

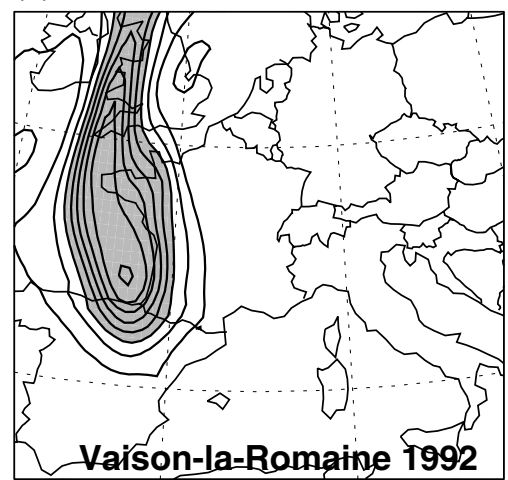

(b)

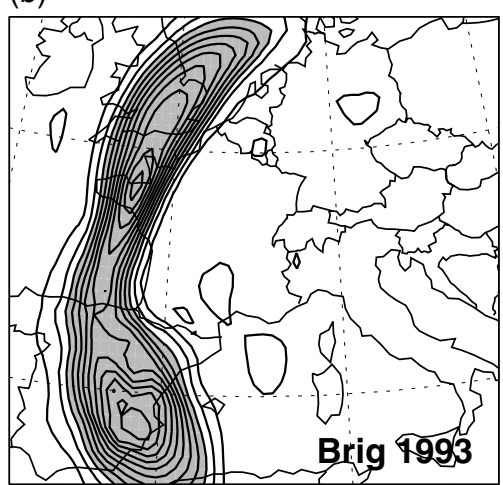

(c)

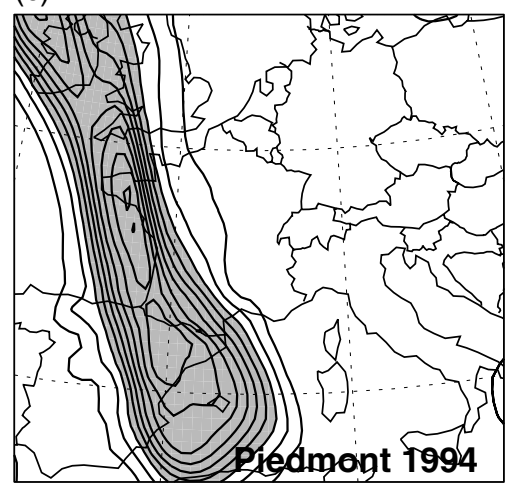

(d)

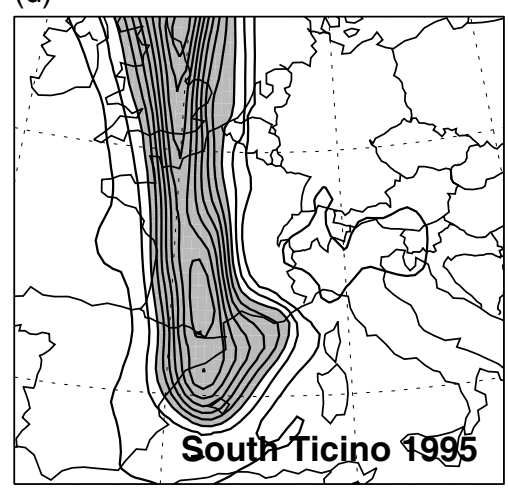

(e)

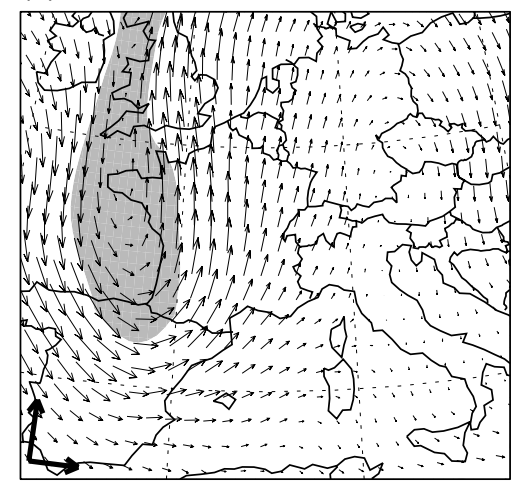

(f)

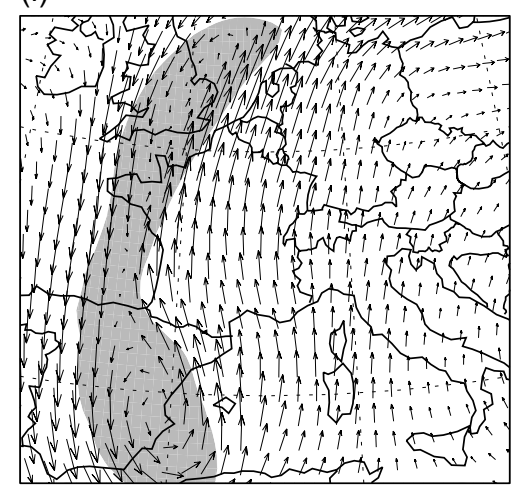

(g)

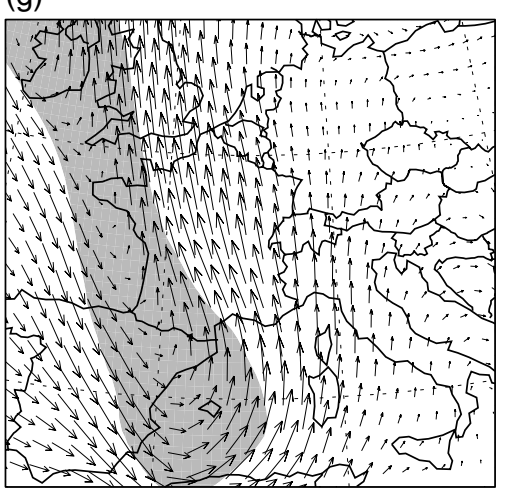

(h)

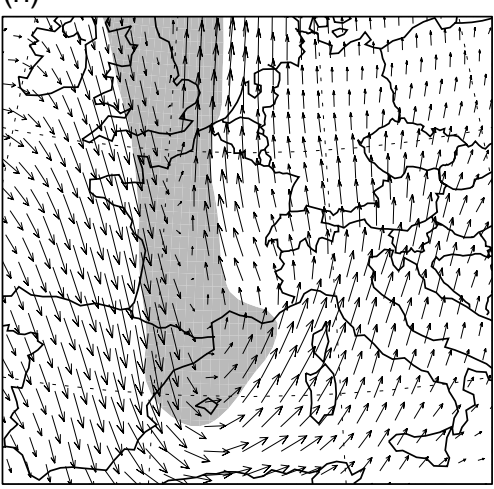

(i)

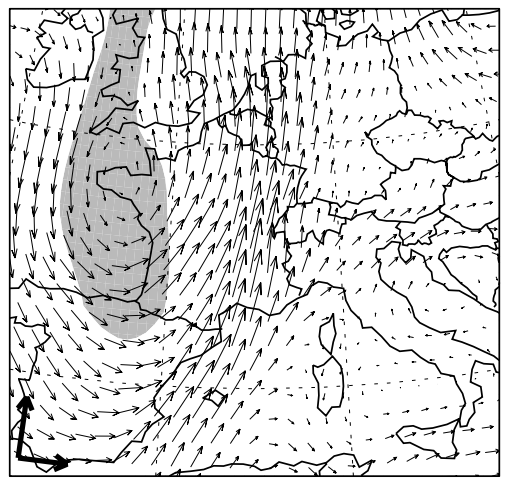

(j)

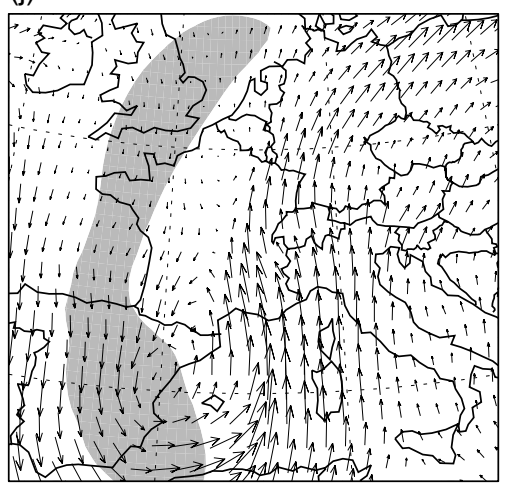

(k)

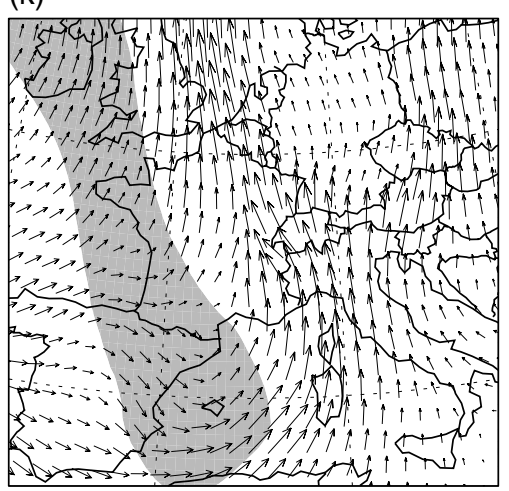

(I)

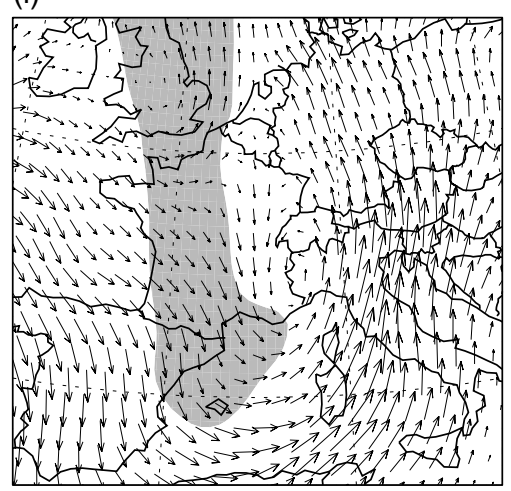

Figure 2. Depiction of four flood-related events derived from ECMWF analyses: Vaison-la-Romaine (06 UTC, 22 September 1992, first row); Brig (12 UTC, 23 September 1993, second row); Piedmont (18 UTC, 05 November 1994, third row); South Ticino (12 UTC, 13 September 1995, fourth row). The display time corresponds to $\sim 6$ hours before the heaviest precipitation. (a) - (d) show PV (with contour interval 1 pvu, starting at $1 \mathrm{pvu}$ ) on the $\theta=320 \mathrm{~K}$ surface, (e)-(h) the horizontal wind field on the same surface, and (i) -(l) the horizontal wind on the $700 \mathrm{hPa}$ surface. In each panel the shaded area denotes PV $>3$ pvu on the $\theta=320 \mathrm{~K}$ surface. The scale of the displayed arrows is (e) $60 \mathrm{~m} \mathrm{~s}^{-1}$ at the $\theta=320 \mathrm{~K}$ surface and (i) $30 \mathrm{~m} \mathrm{~s}^{-1}$ at $700 \mathrm{hPa}$. 
context it is interesting to record that, during the MAP Special Observing Period (SOP), elongated streamers occurred above the Alps or the near vicinity on 7.5 days (Steinacker, 2000).

A more comprehensive climatology of the relationship between heavy precipitation along the Alpine south side and upper-level streamers over western Europe has been compiled recently (Martius et al., 2006) for the 1966-1999 period. It was based upon the ERA-40 dataset (Uppala et al., 2005) for the upper-level flow, and the Alpine-wide daily time series of area-mean precipitation dataset of Frei and Schär (1998) for the precipitation events. The approach adopted was to derive climatologies based upon comparison of days with high precipitation (HP) for a geographical band along the Alpine south side (and also for three Alpine sub-regions) with days when streamer-like features were present in the upper levels immediately west of the Alpine chain.

The derived climatology supports the 'streamerprecipitation' link outlined in the previous section. For example for the period 1966-1999 there were 124 days of extreme precipitation (defined as having more than $29 \mathrm{~mm}$ precipitation) on the Alpine south side, and on 91 (i.e. $73 \%$ ) of those days there was an upper-level streamer located immediately west or north-west of the Alps. Note also that the extreme precipitation days exhibit a seasonal variation with a maximum in autumn of 55 days, and a streamer is present on $85 \%$ of those days.

It is also pertinent to note that

(1) the composite of the upper-level streamers over Western Europe on the extreme days has a spatial structure resembling the case-studies considered in the previous section (Figure 2),

(2) most of the other days in the extreme precipitation category were characterized by a southern cut-off to the streamer (cf. the pattern accompanying lee cyclogenesis), and

(3) analysis of a second category of precipitation events $\left(\geq 16 \mathrm{~mm} \mathrm{~d}^{-1}\right)$ shows a similar seasonal variation for the precipitation days whereas the accompanying seasonal variability for co-occurrence of streamers is less - pointing to the influence of other meteorological factors.

The composite approach mentioned above has also been extended (Martius, 2005) to examine the lagged composite structures of the upper-level PV. The lagged patterns for the non-summer seasons show that a significant precursor signal is traceable upstream to the eastern Pacific over a time period of up to 6 days. This has implications for prediction and will be discussed again in a later section. For the summer season, the signal has an essentially in situ character and points to the possible role of deep convection and orographic effects.

In a related approach, Hoinka et al. (2006) used a regression approach to determine lagged crosscovariances of specific free atmosphere fields (analysis taken from ERA-40 data) with those of regional Alpine rain rates. In this study a time series was applied with days having more than $29 \mathrm{~mm}$ of precipitation on the Alpine south side (HP days) which was already used by Martius et al. (2006). A sample of the results is shown in Figure 3 which displays the cross-covariance of PV at $\theta=320 \mathrm{~K}$ and the area-mean precipitation for (a) $\tau=$ -2 , (b) $\tau=-1$, (c) $\tau=0$ and (d) $\tau=+1$ (days). In addition to the anticipated peak at zero time lag, note that at zero lag the strength of the linkage corresponds to a maximum of about $14 \mathrm{pvu}$, and gradients in the PV patterns attain their strongest intensity close to the Alps with a distinctive indentation on the eastern periphery immediately above the Alps. This indentation is not evident before $\tau=-56 \mathrm{~h}$ and after $\tau=+18 \mathrm{~h}$, and hence points to a strong Alpine influence upon the streamer. Again we comment further on this feature in a later section.

The regression fields show the typical geographical position of the PV streamer when flooding occurs at the southern side of the Alps. However, the general appearance of the regression-based 'PV streamer' has a more elliptic-type structure than the usually observed meridionally elongated streamer pattern. Also the climatological study of Martius et al. (2006) exhibited a weakly meridionally stretched pattern.

\section{The special observing period of MAP}

The SOP of the MAP was timed for the autumn, in line with the predilection for HP events during this season. The observational strategy for the streamer component
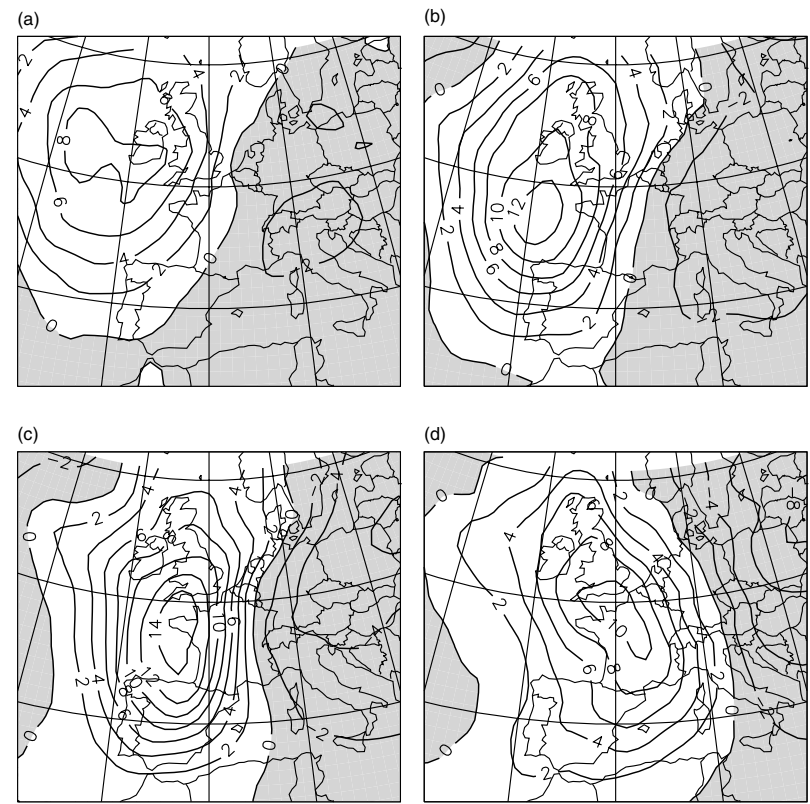

Figure 3. Cross-covariance functions of heavy precipitation on the south side of the Alps with the PV field at $\theta=320 \mathrm{~K}$ normalized by the standard deviation $\sigma$ of the precipitation so that the resulting fields can be interpreted in units of pvu, with contour interval 2 pvu. Time lags (days) are (a) $\tau=-2$; (b) $\tau=-1$; (c) $\tau=0$; (d) $\tau=+1$. The hatched area indicates negative cross-covariance function. The series contains all autumn days from 1966 to 1999. (Taken from Hoinka et al., 2006). 
had several ingredients. It relied primarily on the deployment of the German Falcon aircraft during a PV streamer episode. There was an on-board DIAL instrument to provide measurements of lower-stratospheric and uppertropospheric humidity. In addition, the fixed surfacebased French network of VHF profilers (Caccia et al., 2001) could provide continuous measurements of the three wind components and of the tropopause height during the passage of the anomalies over the network. A further possible data resource was the increased number of sondes launched during an intensive observation period (IOP).

The MAP field phase ran from the first week of September to mid-November 1999, and the Falcon was available from mid-October to the end. In the latter time-slot there were three streamer episodes over central Europe on 27 October (IOP 11), 6-7 November (IOP 15), and 15 November (IOP 17). The focus here is on the latter two events. During this period the ECMWF model operated with the version T319L60.

\subsection{The IOP 15 episode}

For the first event (5-8 November) an overview of the streamer's evolution is provided in Figure 4. On 5 November the streamer evolved rapidly, elongating southwards from the large PV reservoir north-west of Europe. It approached the Alps on 6 November, and crossed the mountain chain the following day, in the process undergoing a further elongation and acquiring a spiral form to the south.

On 6 November, there were indications of cyclogenesis under the streamer's southern tip, and the streamer itself acquired two separate PV centres on its northern and southern extremities. On 7 November, the southern centre had almost cut off, and later that day the streamer dissolved over the Alps whilst contributing to a weak lee cyclone to the south. The two separate PV centres remained the following day, one above north-eastern Germany and the other above Sicily. Further details of the streamer's evolution have been compiled (Liniger and Davies, 2003; Hoinka et al., 2003).

The streamer was not optimally located (Figure 4) to generate an Alpine HP event. This is confirmed by inspection of Figure 5. The streamer is several degrees too far east, as is the accompanying broad lowtropospheric southerly flow (Figure 5(c)). However starting from 06 UTC on 6 November, the lee cyclone produced a 24-hour accumulated precipitation of 50-60 mm, mostly in north-eastern Italy (Buzzi et al., 2003).

Other notable features of the episode are the asymmetry in the wind strength across the streamer (Figure 5(b)), moderate föhn above the Alps between 5 and 6 November, and a strong mistral at the south-western edge of the Alps (Guenard et al., 2005). The latter two lowlevel features are clearly evident in the ECMWF analysis (Figure 5(c)).

\subsection{The IOP 17 episode}

The second streamer event occurred on 15 November, and its somewhat convoluted evolution, as captured in the ECMWF analysis, is shown in Figure 6. On 12 November an isolated PV streamer that was a remnant of an earlier development arched from eastern Europe to its tip over the Iberian Peninsula. In the period from (a)

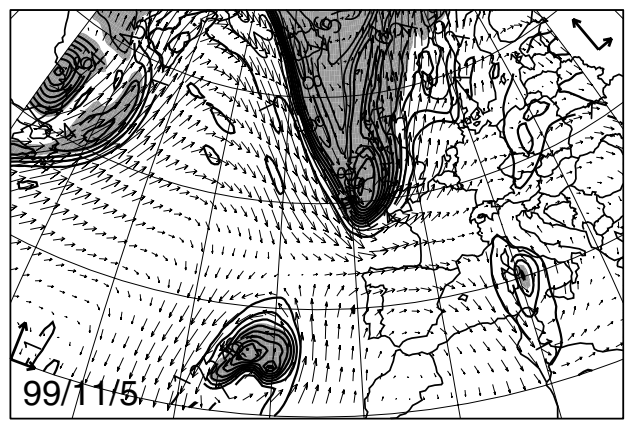

(c)

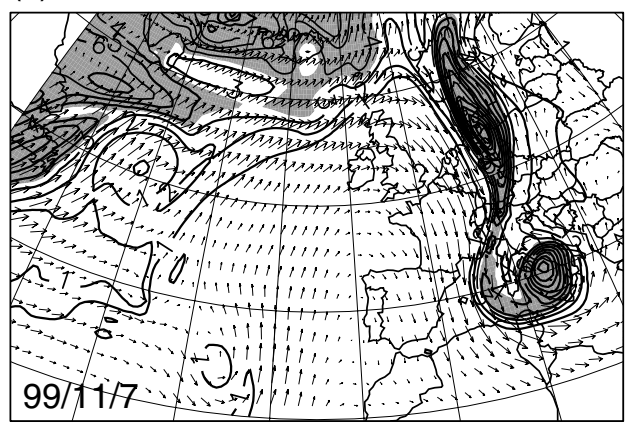

(b)

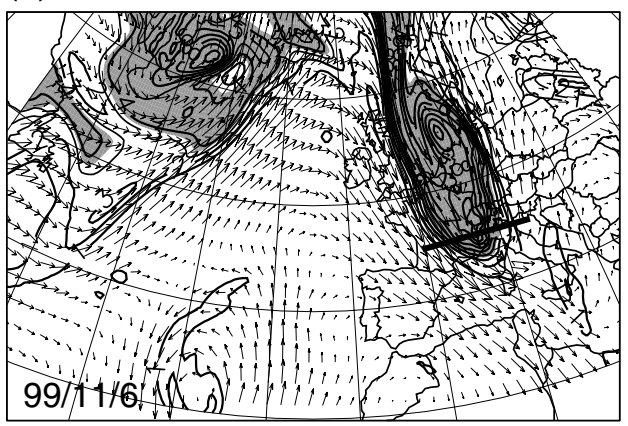

(d)

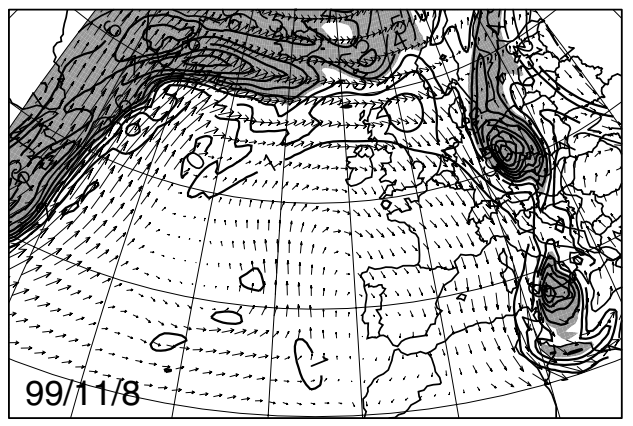

Figure 4. As Figure 1, but for IOP 15 (5-8 November 1999, 12 UTC); the bold line in (b) indicates the baseline of the aircraft flight. 
(a)

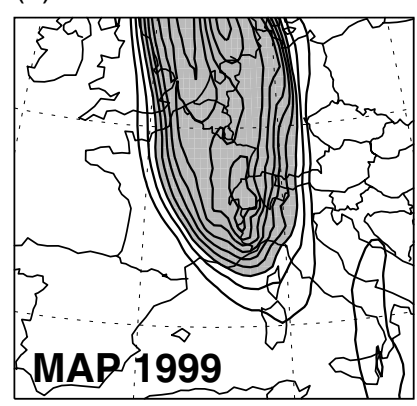

(b)

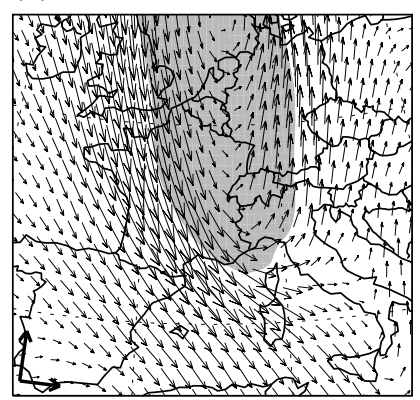

(c)

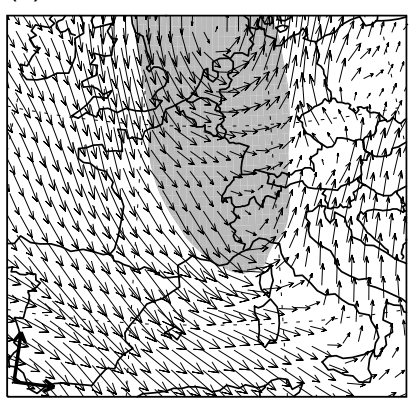

Figure 5. As Figure 2, but for MAP IOP 15 (6 November 1999, 12 UTC).

(a)

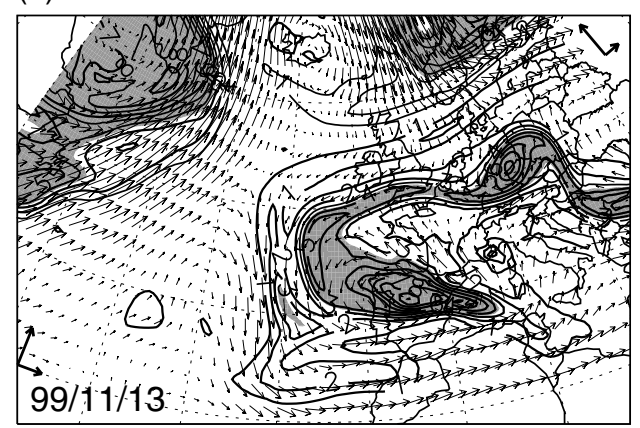

(c)

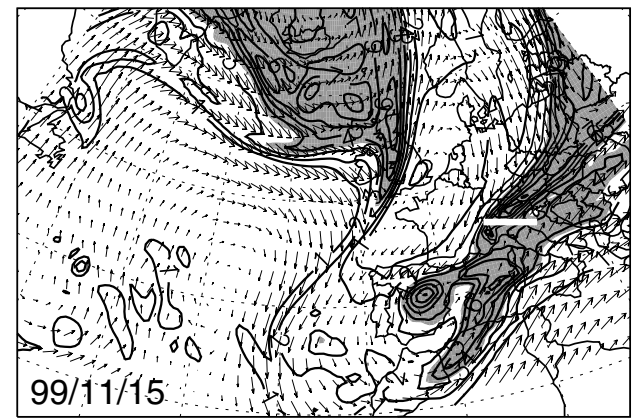

(b)

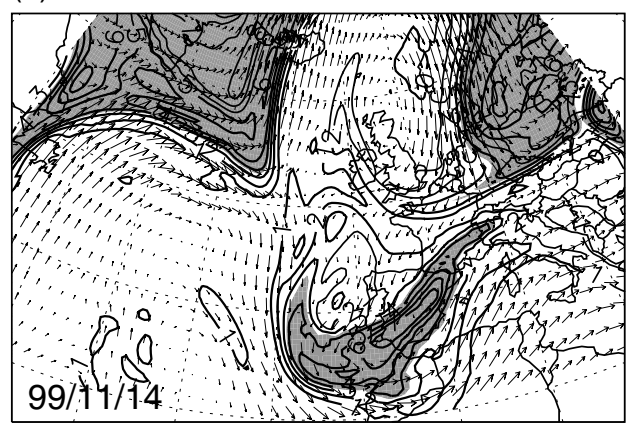

(d)

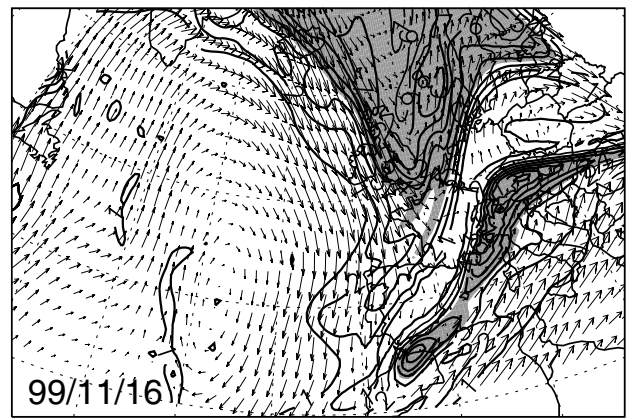

Figure 6. As Figure 1, but for IOP 17 (13-16 November 1999, 12 UTC); the white line in (c) indicates the baseline of the aircraft flight.

13 to 14 November, this elongated streamer split, but on 15 November its northern part reconnected with the stratospheric reservoir over Scandinavia to form a northeast/south-west filament over the Alps. Finally, on 16 November the streamer again separated.

Clearly this remnant feature is not conducive to a heavy precipitation event. However, it does exemplify the intricate structure that the streamers can acquire in their final phase and merits investigation on this account. To this end, a flight mission was undertaken that traversed the streamer between southern Germany and Slovenia at a succession of increasing altitudes.

\subsection{Flights and forecasts}

A key ingredient in planning the execution of a flight mission is the current forecast, and moreover the accuracy of the latter has a direct bearing upon the value of the gathered data. Here we examine the performance of the ECMWF forecasts by evaluating the ECMWF forecast data along the traversed flight paths.
For the IOP 15 event with its more typical slow eastward translation of a streamer, the correspondence of the 1- to 3-day forecast of the event with the verifying analysis (Figure 7(a)-(d)) demonstrates the excellent quality of the ECMWF forecast for the event, and this facilitated successful flight planning.

For the IOP 17 event the objective was to perform cross-streamer measurements on the 15 November (see aircraft baseline in Figure 6(c)), and hence for the planning the focus was on the forecasted location of the streamer's lateral boundaries (as captured for example by the $3.0 \mathrm{pvu}$ or low-humidity contours). Noting that at the flight time the streamer had a north-east/southwest orientation and was almost astride the Alps, the predictions (Figure 8) placed the streamer successively further south-eastwards of its true location in the 1-, 2and 3-day forecasts. This misplacement occurs irrespective of the selected initial dataset (i.e. ECMWF operational or reanalysis fields; Figure 8(c)) and the deployed model resolution (T213/L60 Figure 8(a), or T511/L60 
(a)

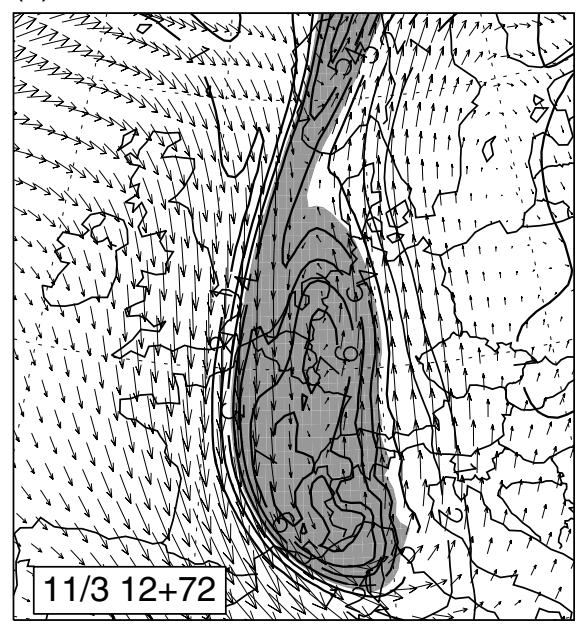

(c)

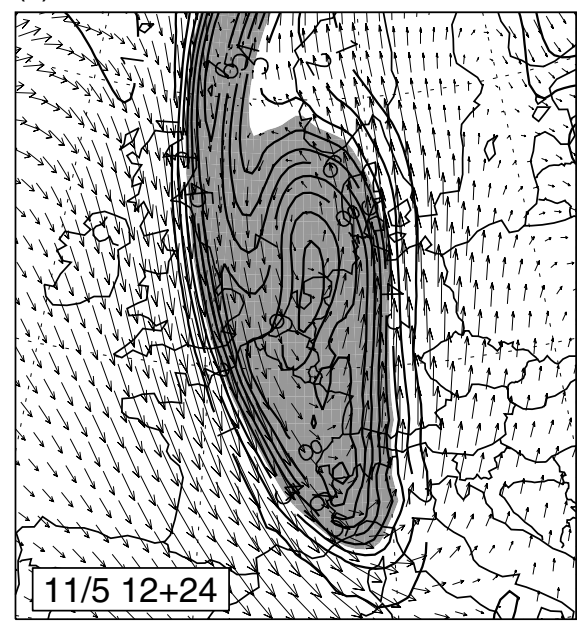

(b)

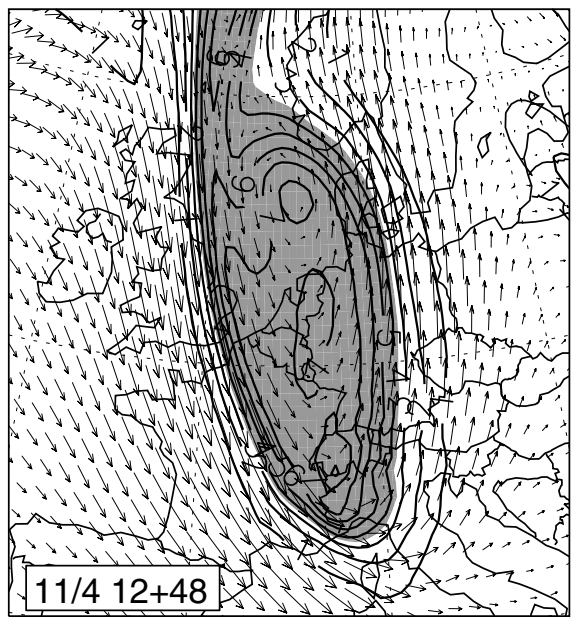

(d)

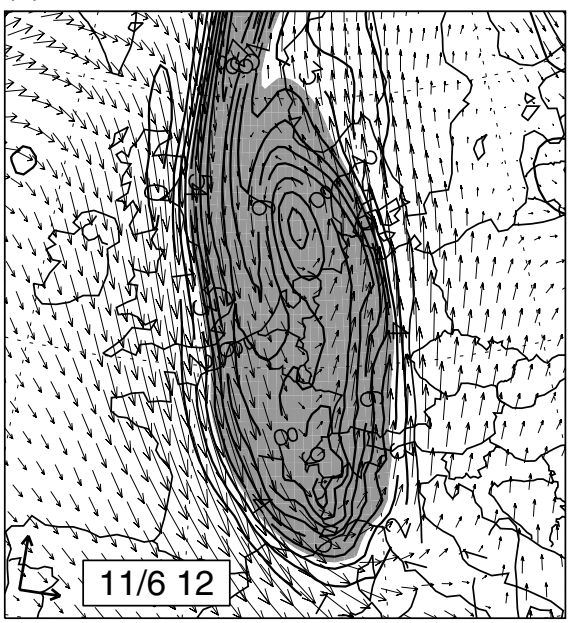

Figure 7. ECMWF (a) 72-hour, (b) 48-hour and (c) 24-hour forecasts and (d) analysis of wind and PV at $320 \mathrm{~K}$, all valid at 12 UTC on 6 November 1999 (IOP 15). The PV contour interval is 1 pvu, and the shading marks PV > 3.5 pvu. The scale of the displayed arrows in (d) represents a wind of $60 \mathrm{~m} \mathrm{~s}^{-1}$ and is correct at latitude $41^{\circ} \mathrm{N}$.

Figure 8(b)). Note further that a 3-day forecast with the T312 version did not replicate the filament, whereas the 1-day forecast allowed reasonable flight planning for the purpose at hand.

\section{Humidity measurements within the streamer}

Little was known of a streamer's internal humidity structure prior to MAP. From a dynamical standpoint, it is of interest to know the degree of mixing within a streamer and to determine the nature of the sub-structures both within and on the lower boundary of a streamer. From an observational standpoint, the challenge was to develop an instrument capable of providing humidity measurements in the dry low-stratospheric air.

In the run-up to the MAP field programme, the DLR developed a new version of their airborne water vapour differential absorption lidar (DIAL) system based on a narrow-band tunable dye laser operating in the near infrared (Ehret et al., 1993; Poberaj et al., 2002) that was capable of providing humidity measurements in regions of low water-vapour content. Its potential was shown in a cross-streamer measurement flight conducted in the pre-MAP phase (Ehret et al., 1999). Hence for MAP the DIAL instrument offered the unique opportunity to measure water vapour mixing ratios along extended cross-sections passing through the streamer.

Flights were performed for both the IOP 15 and IOP 17 episodes. For the IOP 15 streamer, two acrossstreamer measurement flights separated by about $300 \mathrm{~km}$ sampled the humidity distribution of the slowly eastwardmoving feature. Hoinka et al. (2003) gives a detailed comparison of the DIAL data with ECMWF analysis and MESO-NH model simulation. In general there is a good agreement between the three datasets (e.g. their Figure 6). Another illustration of the compatibility is given in Figure 9, which shows scatter plots of the analyzed (ECMWF) and simulated (MESO-NH) versus measured (DIAL) mixing ratios for 6 November. (For comparison purposes, note that the MESO-NH operated with a horizontal resolution of $8 \mathrm{~km}$ and 50 vertical levels). Note also that 
(1) the scatter is much smaller for mixing ratios lower than 50 ppmv than for larger values, and

(2) structural differences are comparatively small particularly for values less than 100 ppmv.

In statistical terms the correlation coefficient, $C$, measuring the relation between the two data series indicates a strong similarity. For the range 10-100 ppmv (all three datasets), $C=0.80$ for both the DIAL/MESO$\mathrm{NH}$ and DIAL/ECMWF fields, and the error is comparatively small $(\approx 0.005)$. Likewise the inter-relationship captured by the regression coefficient is $R=0.83$ for the DIAL/MESO-NH mixing ratios and $R=0.95$ for the DIAL/ECMWF set. In effect, for water vapour mixing ratio, the three datasets compare reasonably well. The DIAL data of IOP 15 has also provided a validation base for the ECMWF MAP reanalysis dataset (Keil and Cardinali, 2004).

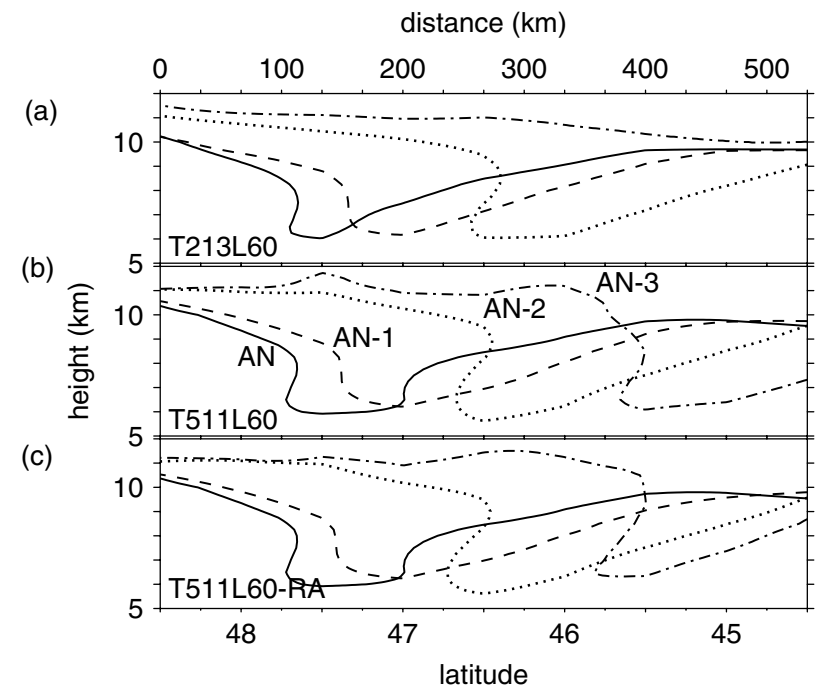

Figure 8. Analysed and forecast cross-sectional height of the $P V=3.0$ pvu surface above the baseline given in Figure 6(c), as determined by ECMWF at 12 UTC for all days: (a) routine ECMWF analysis T213/L60, (b) T511/L60, (c) reanalysis T511/L60. Analysis (AN, full lines), forecast on day 1 (AN-1, dashed), forecast on day 2

(AN-2, dotted), and forecast on day 3 (AN-3, dash-dotted).
Here we focus on the IOP 17 event. For this episode, four traverses across the streamer, each of some $400 \mathrm{~km}$ length, were performed at increasing height above the same baseline from $48.5^{\circ} \mathrm{N} / 10.5^{\circ} \mathrm{E}$ to $45.5^{\circ} \mathrm{N} / 13.5^{\circ} \mathrm{E}$ (i.e. from near Munich in Germany to Trieste in Italy). The baseline is displayed in Figure 6(c), and these tracks through the streamer's core correspond to analysis values of up to 7 pvu in the ECMWF fields. Figure 10 shows the cross-sectional humidity distributions obtained from the four sequential traverses. In the upper part $(8-10 \mathrm{~km})$ there is little change over the 3-hour flight duration. In contrast, the streamer's lower boundary descends with time. (The $70-80 \mathrm{ppmv}$ layer is at $5.5 \mathrm{~km}$ in the earliest traverse and at $4.5 \mathrm{~km}$ in the latest.) The variation is attributable in part to temporal development and/or advectively induced changes. In addition we note that

(1) in the lower regions there is also evidence of vertically aligned humidity plumes of $40-70 \mathrm{ppmv}$, and

(2) the position of the eastern edge of the streamer remains unchanged with time (indicating that the streamer did not move further south-eastwards), whereas the decrease in humidity in the $6-8 \mathrm{~km}$ layer is consistent with a downward penetration of the field's core.

The average of all four sections is juxtaposed in Figure 11 with the independent ECMWF analyses and mesoscale model data. It is clear that (as for the IOP 15 event) the three sections exhibit a similar overall structure but with significant sub-structural differences. In particular there are differences in the streamer's fold structures. The DIAL humidity measurements and MM5's PV and humidity fields show folds located on both the poleward and equatorward sides of the north-east/south-west aligned streamer. The DIAL data is consistent with a major descent of dry stratospheric air whereas the MM5 humidities are not as low as the measurements. (For comparison purposes note that the MM5 operated with a horizontal resolution of $15 \mathrm{~km}$ and 59 vertical levels). In contrast the ECMWF analysis captures only the poleward-located fold.

A comparison of humidity data taken from DIAL, the MM5, dropsondes, and the in situ aircraft is shown

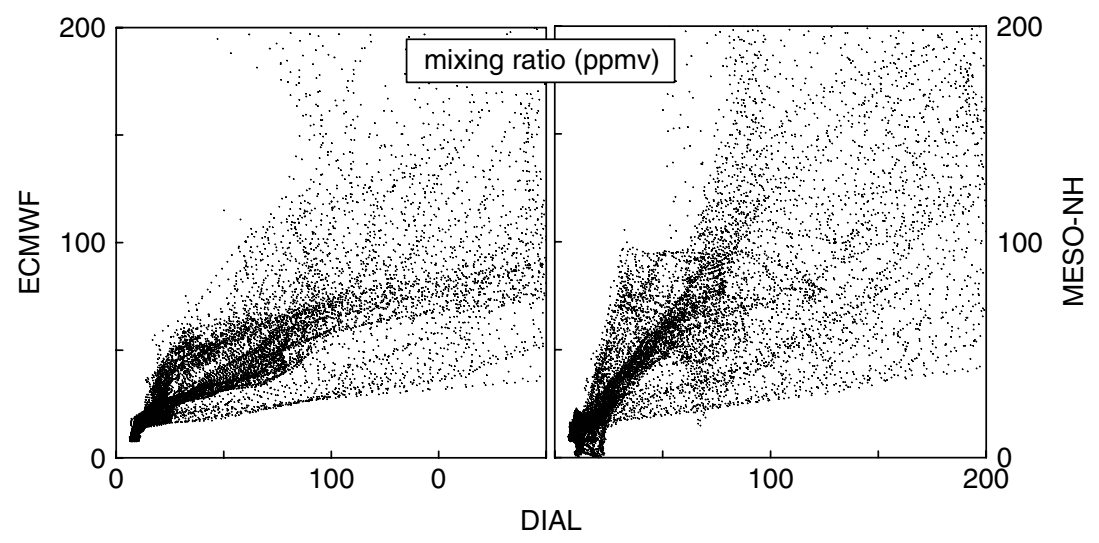

Figure 9. Scatter plots of mixing ratio (ppmv) as analyzed (ECMWF), simulated (MESO-NH), and measured (DIAL) on 6 November 1999 (taken from Hoinka et al., 2003). 


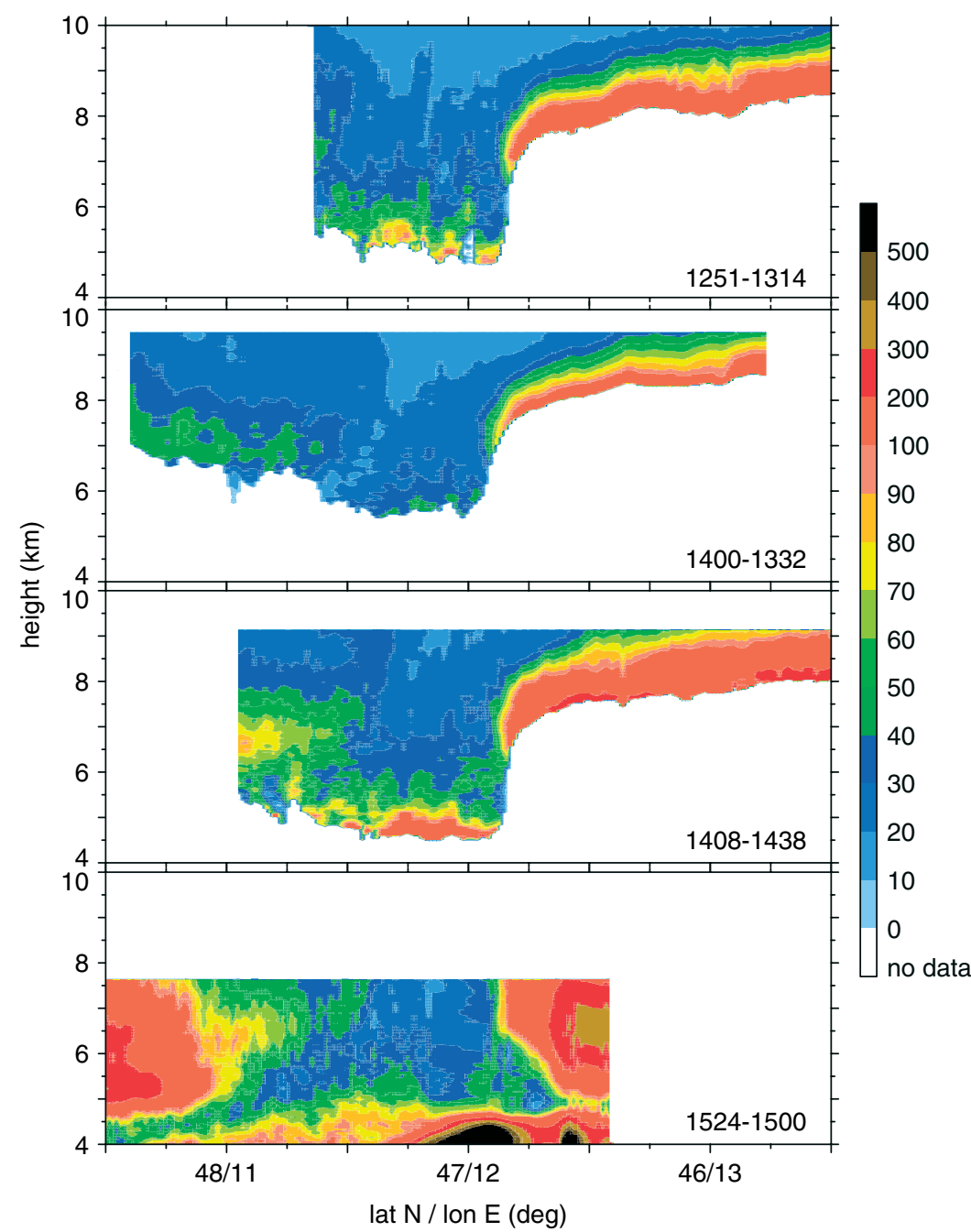

Figure 10. Four cross-sections of DIAL water vapour mixing ratio (ppmv) on 15 November 1999 taken above the baseline given in Figure 6(c). The flight times are given in UTC. The mixing ratio is given by the colour shading; the increment is 10 ppmv below the 100 ppmv contour and 100 ppmv above 100 ppmv.

in Figure 12(a-d), which correspond respectively to vertical profiles through the poleward fringe, core, eastern fringe and equatorward fold of the streamer. At the equatorward fold (Figure 12(d)) the DIAL and sonde data provide independent and corrobating detection of the fold's lower and upper boundary, but the MM5 fails to capture the fold's moisture signal. At the eastern fringe (Figure 12(c)) the DIAL provides some indication of tropospheric air above a shallow fold at an altitude between 6 and $8 \mathrm{~km}$, whereas the sonde data hints at a shallower moist layer around $7.5 \mathrm{~km}$. At the core (Figure 12(b)) the DIAL and dropsonde data are in excellent agreement wheras the MM5 profile is slightly moister. At the poleward fringe (Figure 12(a)) the DIAL data hint at a deeper penetration of the fold than the other two profiles, the sonde data hint at the existence of an upper boundary to a fold at around $7.5 \mathrm{~km}$, and within the streamer there is a pleasing agreement between the DIAL and sonde data. Note that Poberaj et al. (2002) estimated that the deviations between DIAL and dropsonde humidity amount to around 3\% in the near-distance DIAL measurements and up to $12 \%$ in the far-distance ones. Also note that repetition of the ECMWF analysis using the MAP reanalysis data (Keil and Cardinali, 2004) does not result in the appearance of the south-east fold, although there is now a hint of a weak fold in the PV pattern (Figure 13). The centre core of the streamer was drier in the reanalysis data.

Another aspect worthy of note is the appearance in the MM5 simulations of fine-scale wave-like structure of the PV in the tropopause region beneath the equatorward flank of the streamer (Figure 11(b)) that is located above and east of the Alps. These are reminiscent of similar features obtained with the MESO-NH simulations for the IOP 15 event (Hoinka et al., 2003; their Figure 6). It is conceivable that these features are numerical artifacts induced above rough orography and attributable to the limitations of terrain-following coordinate systems which can be ameliorated by the adoption of a more refined vertical-coordinate system (Schär et al., 2002). Indeed, the noisy PV structure at the eastern edge of the IOP 15 streamer was strongly reduced by the application of the smoothed coordinate system (Hoinka and Zängl, 2004). However the wave-like features considered here for the 


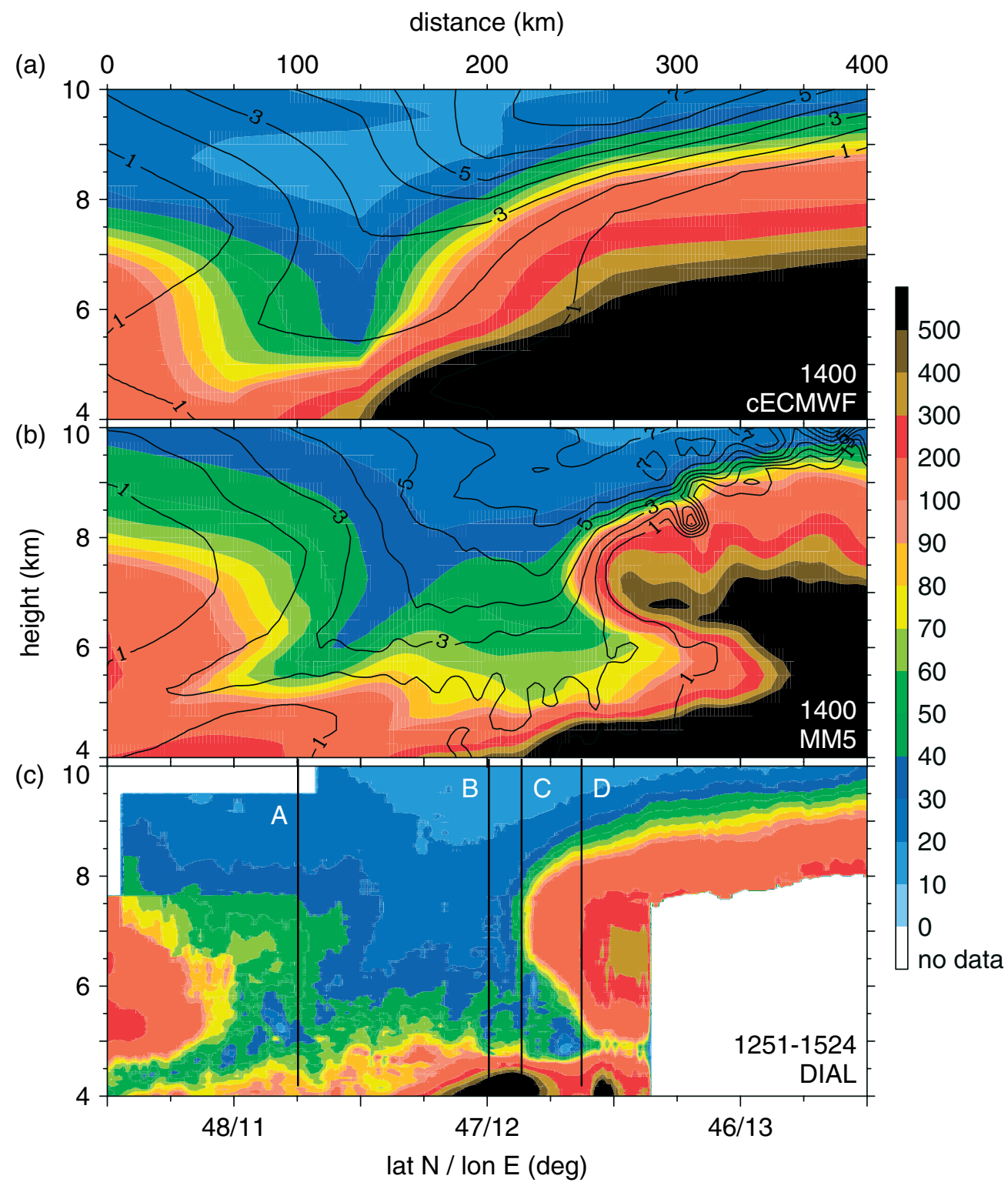

Figure 11. Cross-sections of water vapour mixing ratio (ppmv) for 15 November 1999 taken above the baseline shown in Figure 6(c): (a) shows interpolated ECMWF operational analysis from 1400 UTC, (b) data simulated by the mesoscale model MM5 from 1400 UTC, and (c) data taken by the DIAL between 1251 and 1524 UTC. The MM5 simulation started at 00 UTC on 15 November. The scaling for the humidity is as Figure 10. The black contours in (a) and (b) denote PV, with interval 1 pvu. The vertical lines in (c) indicate the locations of the vertical profiles shown in Figure 12.

(a) (b)

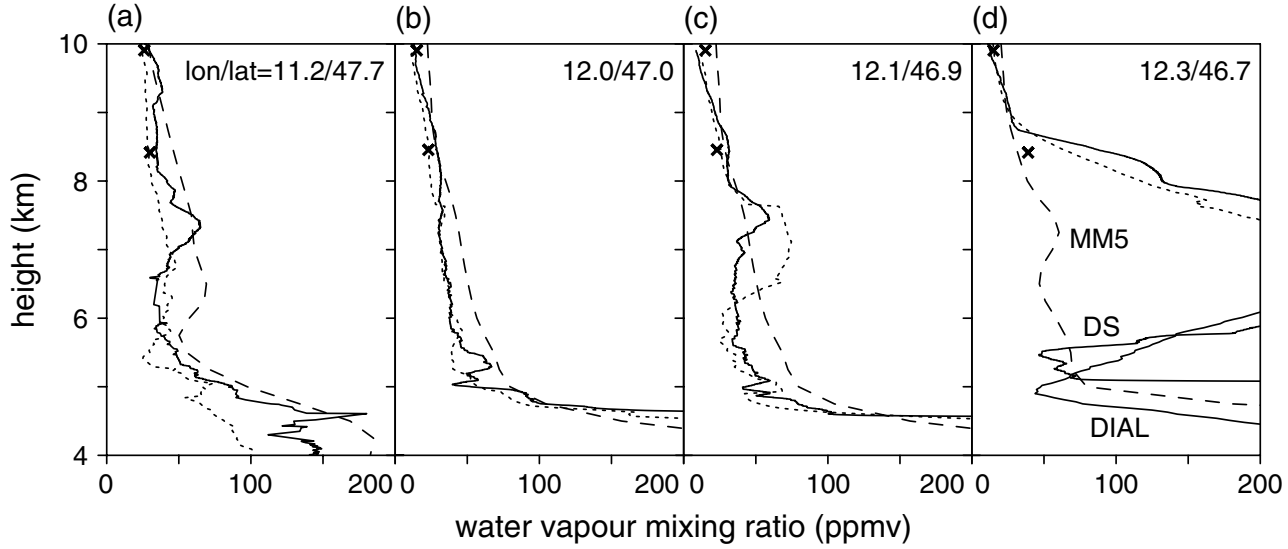

Figure 12. Comparison of vertical humidity profiles (ppmv) for 15 November 1999 (IOP 17) from DIAL (dotted), MM5 (dashed), dropsonde (DS, solid), amd in situ aircaft (crosses). A-D represent vertical profiles through the poleward fringe, core, eastern fringe and the equatorward fold of the streamer, respectively. The position of the vertical profiles is given in each panel and also indicated in Figure 11(c). 
(a)

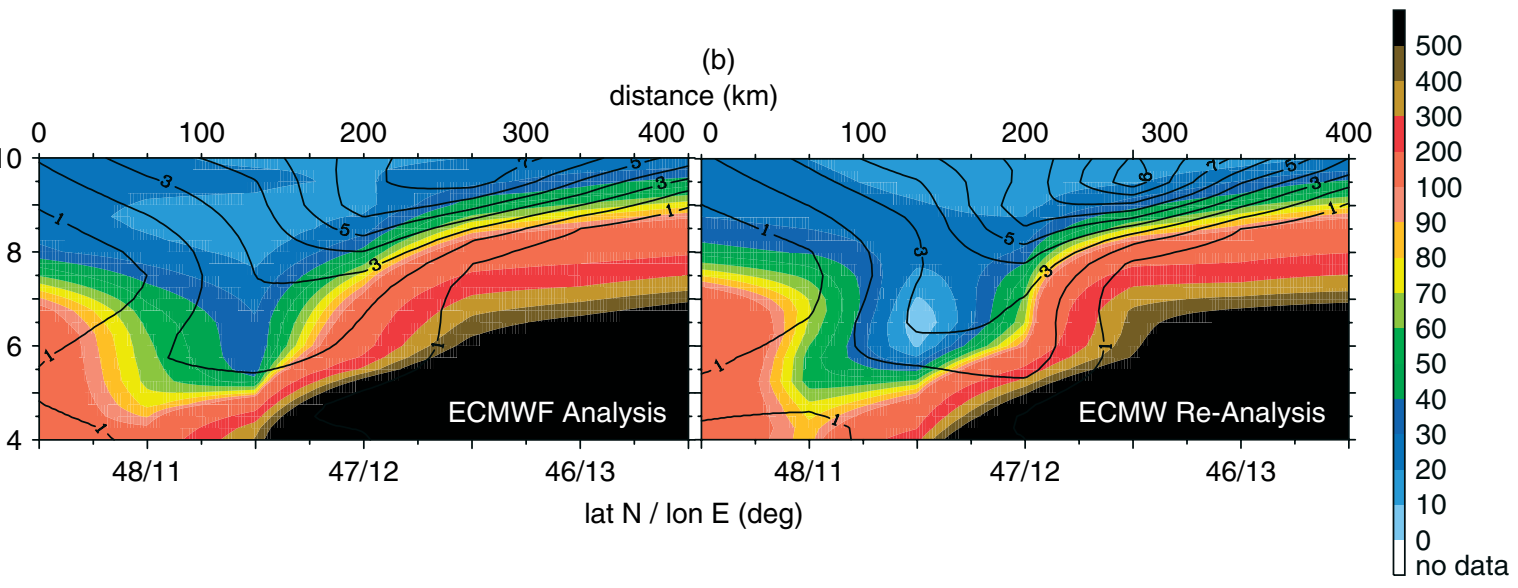

Figure 13. Temporally interpolated (14 UTC) ECMWF cross-sections of water vapour mixing ratio (colour shading, ppmv) on 15 November 1999 above the baseline given in Figure 6(c): (a) operational analysis, and (b) reanalysis. The black contours denote PV (with interval 1 pvu). This figure is available in colour online at www.interscience.wiley.com/qj

IOP 17 episode remain even when the MM5 is operated with the refined coordinate system, and moreover they are lent further credence by surface and satellite observations indicating that precipitation and clouds were present at this eastern edge of the streamer over the Dalmatians.

In summary, we note that the three kinds of datasets considered (ECMWF, mesoscale model, DIAL) are remarkably disparate, and each undergoes markedly different processing - assimilation for the ECMWF, numerical simulation for the MESO-NH and MM5, and horizontal and vertical averaging for the DIAL. These differences certainly impact upon the resulting fields, but an intercomparison between the IOP 15 and 17 events indicates that

(1) the streamer's zonal boundaries are in good agreement,

(2) the humidities within the descending branch are of comparable magnitude,

(3) the descent of stratospheric air is reasonably well represented,

(4) all three datasets capture the westward-bending fold in IOP 15 , and

(5) two folds appeared in IOP 17 and were simulated by the MM5, whereas the ECMWF analysis captured only one.

In effect, the comparatively coarse-resolution ECMWF analysis data capture only the gross structure of the streamer, but nevertheless give a generally correct picture. The MESO-NH and MM5 models produce some mesoscale features that are reminiscent of those evident in the DIAL data.

\section{Further distinctive structures}

The DIAL measurements clearly indicate that there is a wealth of fine-scale structures within streamers, but their 3D form and temporal evolution remains inadequately observed and therefore by default often unexplained.
However the ECMWF fields point to the prevalence and intricacy of these features.

Further hints can be gleaned from mesoscale numerical simulations of individual events, the use of analysis/model data to derive backward trajectories, allied to the reverse domain-filling technique (Sutton et al., 1994) or Lagrangian forward projection (Liniger and Davies, 2003), and careful interpretation of measurement data gathered during aircraft transects of a streamer. These essentially ad hoc approaches provide a tantalizing glimpse of the sub-structures, and can be used to shed light on some of the fine-scale features in the DIAL dataset.

Here we comment on three such finer-scale structures. The first is the striking fine-scale feature that appeared in both the cross-sectional aerosol measurements of the IOP 15 streamer (see Figure 8 in Hoinka et al., 2003). It took the form of a narrow band of increased backscatter ratio within the western part of the streamer, and extended eastwards with height. Its presence in the two cross-sections separated latitudinally by $300 \mathrm{~km}$ testified to its spatial and temporal coherence. Comparison of the mixing ratio and backscatter ratio fields indicates that the band is located at the top of the descending tongue of dry stratospheric air and possibly within the region of strong gradient delimiting the tongue's top. The band's very-fine-scale structure renders it not easily amenable to simulation with a mesoscale model. However, application of the Lagrangian forward-projection approach suggests (Liniger and Davies, 2003) that the band comprised a sheet of high water vapour sandwiched between another two sheets of drier air, and that each sheet had undergone a geographically and vertically differentiated evolution over the previous 3 days. There are no DIAL water vapour data available to confirm the humidity structure, but the compatibility of the independent observational measurements and the analysis-based backward-trajectory data lends credence to both.

The second fine-scale feature considered here also relates to folds. Both the IOP 15 and IOP 17 streamers 
had folds at their trailing edge and these descended to below $6 \mathrm{~km}$. Small-scale features were observed (D'Aulerio et al., 2005) beneath the streamer in the form of thin dry-air filament-type patches $(0.3-1.0 \mathrm{~km})$ that persist for at least $48 \mathrm{~h}$. They were detected using a ground-based Raman LIDAR installed in northern Italy at $45.9^{\circ} \mathrm{N} / 8.5^{\circ} \mathrm{E}$ south of Lago Maggiore during MAP SOP. The instrument enables small-scale areas of dry stratospheric intrusions to be detected between the boundary layer and the mid-troposphere, provided that there is no sunlight. Supportive evidence is available from vertical profiles derived with radiosondes from the nearby station Milano. The dry signature of the filament $\left(\approx 0.2 \mathrm{~g} \mathrm{~kg}^{-1}\right)$ was clearly detectable at altitudes of less than $4 \mathrm{~km}$, and was sandwiched between moister layers of $0.6 \mathrm{~g} \mathrm{~kg}^{-1}$. In their temporal evolution, derived from time series of vertical LIDAR profiles, the filaments become narrower with time and penetrate down to about $3.5 \mathrm{~km}$ altitude. Again backward-trajectory computations indicate that they originate from the streamer's core (D'Aulerio et al., 2005). Thus fine-scale features are observed beneath a streamer's fold and originate from it.

A third category of fine-scale features relates to the sharpness of a streamer's lateral boundaries and its finescale interior features. Information on this category can be gained from in situ measurements of quasi-tracers (e.g. aerosol, water vapour and ozone mixing ratio) taken as an instrumented aircraft traverses a streamer. Such measurements are instructive in the light of the strong across-tropopause gradients of these atmospheric constituents. In Figure 14, in situ ozone measurements taken during IOP 17 are juxtaposed with the corresponding across-streamer distribution of model-simulated PV (cf. Figure 11(b)). Inspection of the spatial traces shows that, superimposed upon the general increase of ozone with height in the stratospheric air (typically $100 \mathrm{ppbv}$ at $8.4 \mathrm{~km}$ to $150 \mathrm{ppbv}$ at $11.1 \mathrm{~km}$ ), there are also strong horizontal gradients at the streamer's lateral boundaries. Moreover, these boundaries connote a narrower streamer than that for the model data. This follows from comparing the width of the zone delineated by enhanced values of measured ozone $(\geq 50 \mathrm{ppbv})$ with the zone defined by the model values of $2-3$ pvu. A hint of features that are internal to the streamer is provided by Figure 15 with its series of high-resolution ozone traces (traces $\mathrm{A} / \mathrm{B} / \mathrm{C} / \mathrm{D}$ correspond to flight levels of $11.1 / 10.5 / 9.9 / 8.4 \mathrm{~km}$; see Figure 14). In the streamer's inner core, there are structurally well-defined major ozone variations of $\approx 10-50 \mathrm{ppbv}$.

These features were also evident in the streamer that was associated with the Piedmont flood event of 5 November 1994. Figure 16 displays the measurements of ozone and water vapour mixing ratios gathered in situ during a traverse across the streamer when it was located over England; the flight was conducted within the framework of the Pollution from Aircraft Emissions in the North Atlantic flight corridor project (POLINAT; Schumann et al., 2000). In this case again, the streamer's width, as defined by the constituents, appears significantly less than that indicated by the PV field of the ECMWF analysis. In the period around that of the flight, the streamer was quasi-stationary and deformed only weakly, and hence a reasonable inference is that the

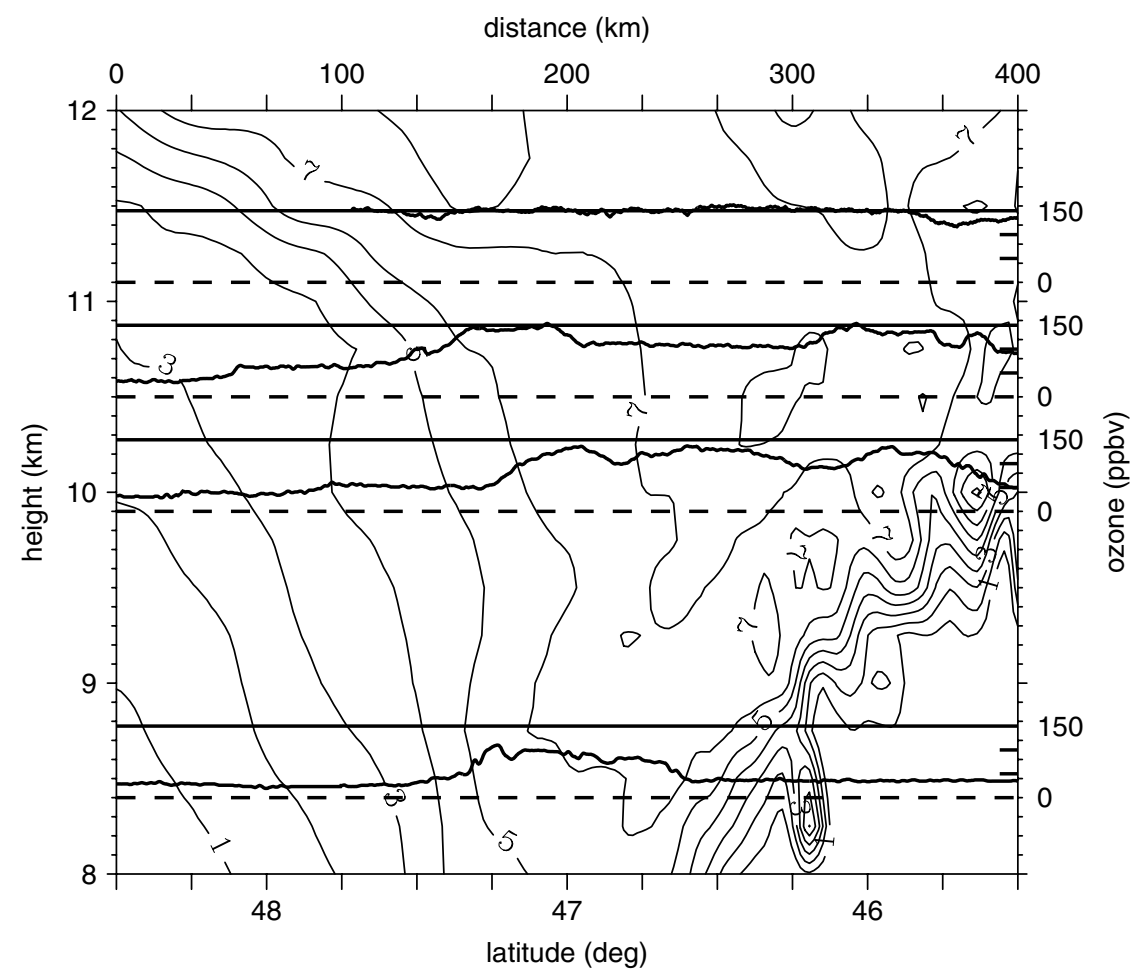

Figure 14. PV simulated by MM5 (pvu; thin contours) and measured ozone (ppbv; bold curves) along the cross-section for IOP 17 shown in Figure 10. The PV pattern is that shown in Figure 11(b). The dashed lines indicate the flight level of the aircraft for the in situ measurements. 


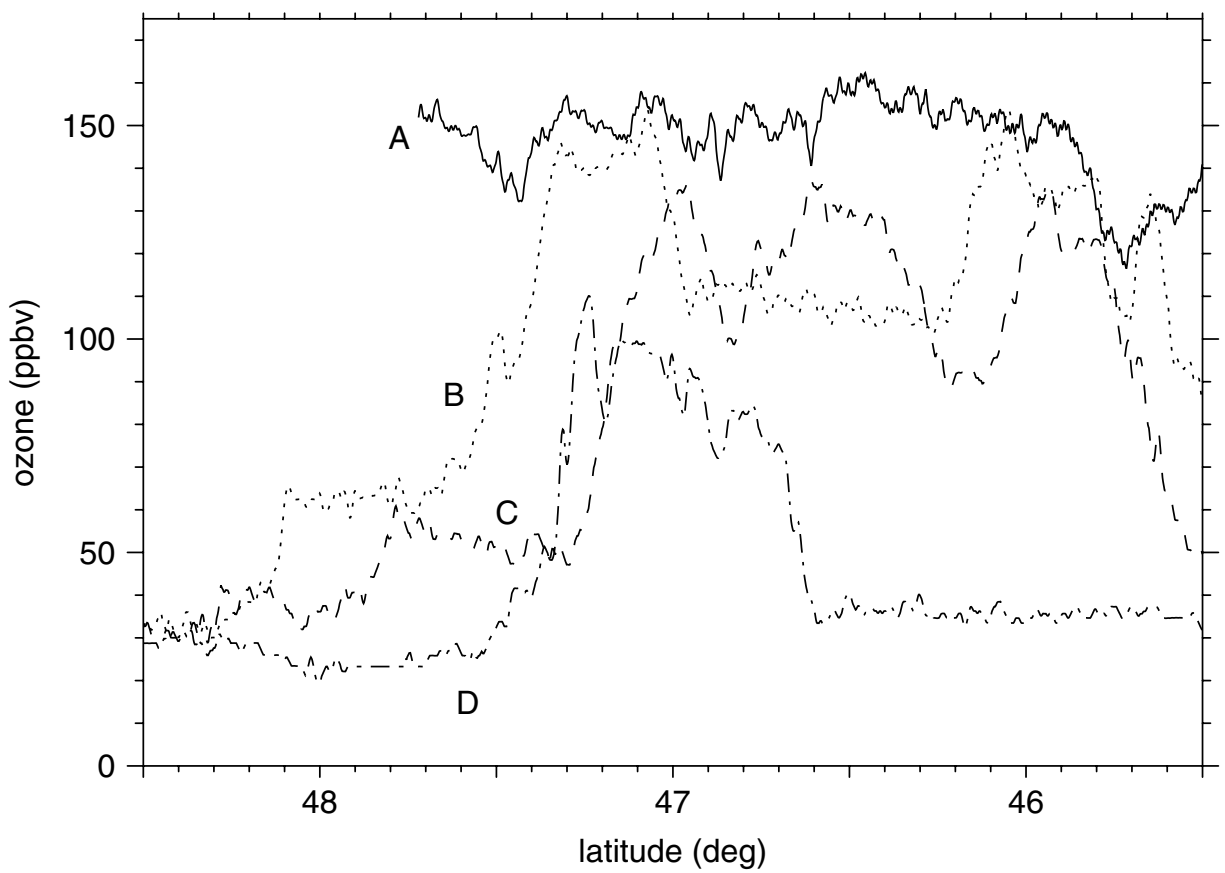

Figure 15. In situ measured ozone (ppbv) along the cross-section for IOP 17 shown in Figure 10. A, B, C and D denote the four flight levels shown in Figure 14.

(a)

(b)

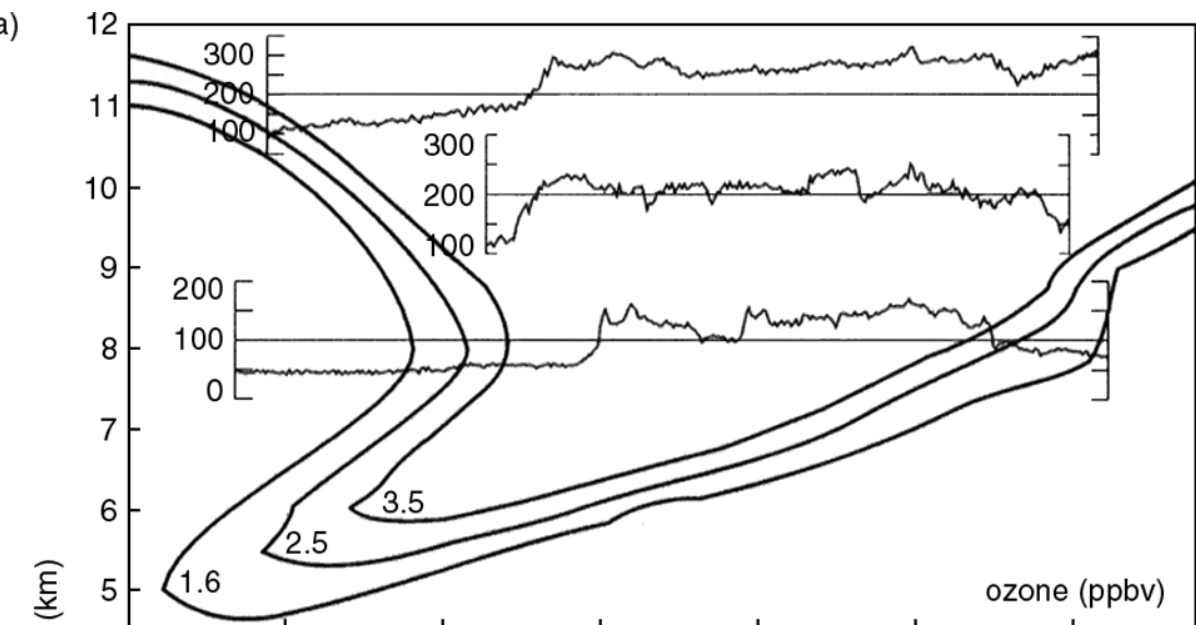

늘

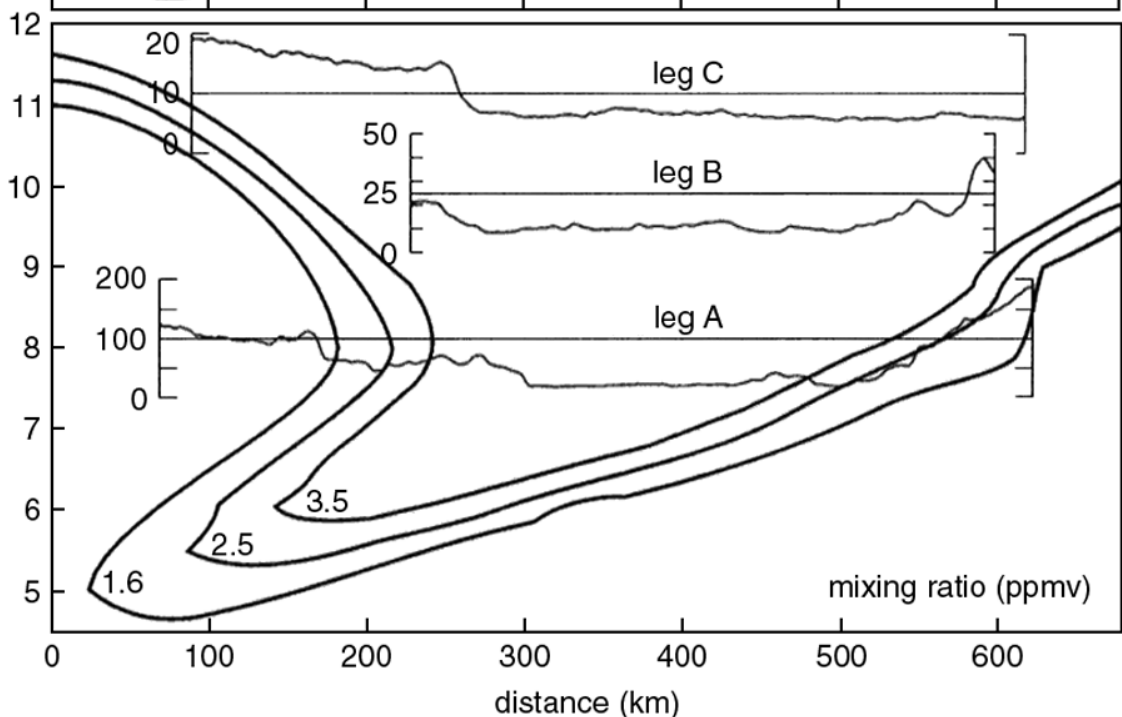

Figure 16. Aircraft measurements of (a) ozone (ppbv) and (b) water vapour mixing ratio (ppmv) within a tropopause fold located over Ireland on 5 November 1994 between $15^{\circ} \mathrm{W}$ and $5^{\circ} \mathrm{W}$ (left to right) along latitude $52.5^{\circ} \mathrm{N}$. The aircraft data were gathered between 0930 and $1230 \mathrm{UTC}$. Contours of PV (pvu; bold solid) are taken from ECMWF operational data at 12 UTC. 
spatial resolution of the ECMWF model is not sufficient to capture the sharp lateral boundaries of the streamer.

Notwithstanding the foregoing caveat, there is a reasonable correspondence between the gross features of the measured and analysed fields. To underline this point, the fields were correlated after a light filter (30-sec running average) was applied to the two measured fields (ozone and water vapour) to remove the rapid/smaller-scale fluctuations. The results (Figure 17) show a correlation of 0.68 between $\mathrm{O}_{3}$ and $\mathrm{PV}$ with the average ratio of $25.2 \mathrm{ppbv}(\mathrm{pvu})^{-1}$. This is to be compared with earlier determined ratios of $45 \mathrm{ppbv}(\mathrm{pvu})^{-1}$ by Danielsen et al. (1987) and of $50.2 \mathrm{ppbv}(\mathrm{pvu})^{-1}$ by Browell et al. (1987). The discrepancy might be attributable either to the difference in aircraft sampling rate of the aircraft data (higher in the present case) and/or to the range of pvu values encompassed in the different studies $(1-7 \mathrm{pvu}$ in the Danielsen et al. (1987) study, and 1-3 pvu in that of Browell et al. (1987)). Additional contribution to the discrepancy might be found in the differing resolutions of, as well as methodologies and datasets used to generate, the PV analyses used in the present study compared with the above-mentioned earlier studies. All these factors might be just as important as the resulting range of $\mathrm{PV}$ in the respective studies.

Likewise, there is a strong negative correlation $(-0.77)$ between PV and water vapour (Figure 17(b)) and between $\mathrm{O}_{3}$ and water vapour (Figure 17(c)), and the corresponding slopes are $-3.6 \mathrm{ppmv}(\mathrm{pvu})^{-1}$ $\left(\mathrm{O}_{3} / \mathrm{PV}\right)$ and $-0.1 \mathrm{ppmv}(\mathrm{ppbv})^{-1}\left(\mathrm{wv} / \mathrm{O}_{3}\right)$. A clear stratospheric signal is evident for the larger $\mathrm{O}_{3}$ values ( $\geq 150 \mathrm{ppbv}$ ) in combination with smaller water vapour values ( $\leq 20 \mathrm{ppbv})$, and to a lesser extent in combination with larger PV values. In contrast, the more scattered distribution for the triplet of lower PV values, lower $\mathrm{O}_{3}$ and larger water vapour, is indicative of the more transient and highly structured airflow at the tropopause.

It is evident from the foregoing discussions of streamer sub-structures that there are significant small-scale structures embedded within, at the boundary of, and below streamers. Their detailed structure, origin and possible effects are little known, but clearly their existence has a direct bearing upon stratosphere-troposphere exchange. In the penultimate section we will comment on the impact of streamer sub-structures upon weather prediction.

\section{Orographic and cloud-diabatic influences}

In earlier sections it was emphasized that a meridionally elongated PV streamer translating toward the Alpine chain is very frequently accompanied by forced ascent of a low-level southerly flow over the chain and the occurrence of heavy precipitation on the Alpine south side. The near approach of the streamer to the chain also implies that the orography and the cloud-induced diabatic heating can influence the streamer itself. One of the subprogramme's objectives was to examine the interaction of a streamer with the orography.
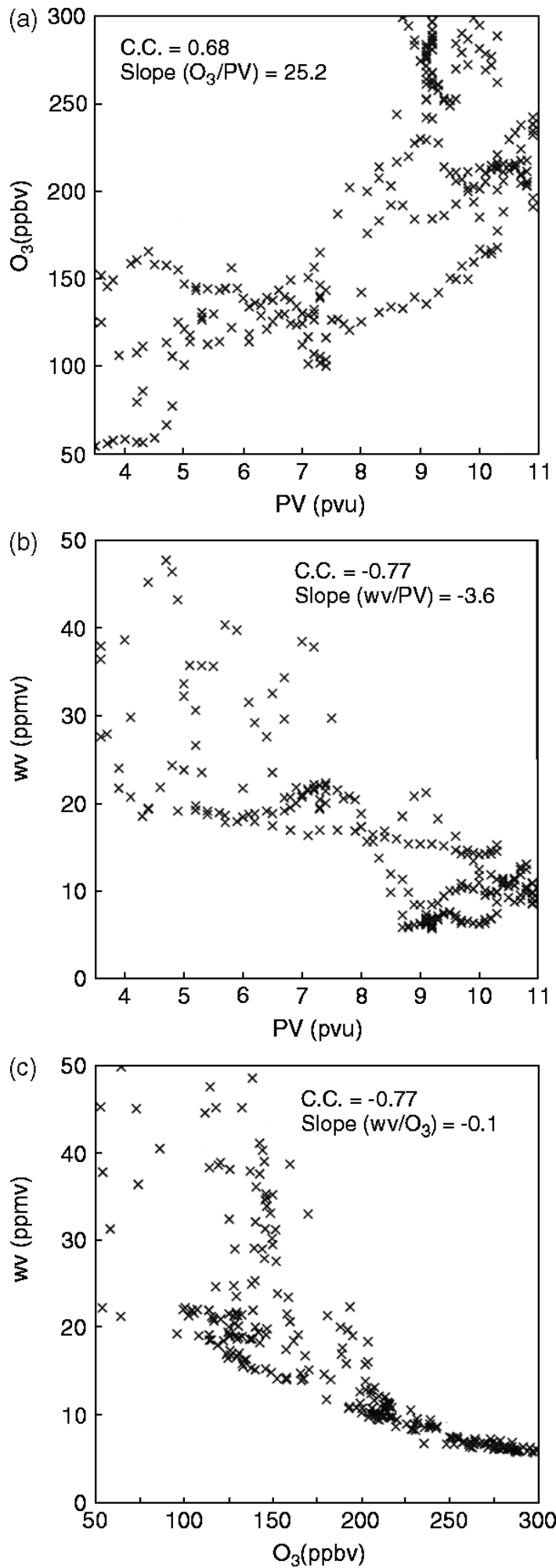

Figure 17. Correlation of (a) $\mathrm{O}_{3}$ and $\mathrm{PV}$, (b) water vapour mixing ratio and $\mathrm{PV}$, and (c) $\mathrm{O}_{3}$ and water vapour mixing ratio in the tropopause fold located over Ireland on 5 November 1994. The correlation coefficient (C.C.) and the regression coefficient (slope) are shown.

Insight has been sought from both model simulations (Morgenstern and Davies, 1999; Buzzi et al., 2003) and the DIAL water vapour measurements (Hoinka et al., 2003). An idealized and case-study analysis using a mesoscale NWP model (Morgenstern and Davies, 1999) 
was designed to examine the separate and combined effects of orography and cloud convection. In isolation the effects in the idealized setting were shown to be comparable in amplitude and significant in influence. The presence of orography beneath the streamer induced lowlevel anticyclones astride the ridge and also mixing aloft attributable to vertically propagating buoyancy waves. Likewise, deep cloud convective activity on the eastern flank of a streamer was accompanied by the outflow of low-PV air on top of the diabatic region, the appearance of a positive PV tower within the diabatic region, and mixing on the streamer's eastern periphery. Both orography and the cloud convective activity led to a thinning of the streamer, and this took the form of an indentation on the eastern periphery of the streamer over the Alps. This resembles the feature noted earlier (Section 3) in the lagged-correlation study. There was also an impact upon the streamer's self-induced movement. In combination, they led to a further thinning of the streamer and the formation of a PV cut-off. Similar results were derived with a similar set of simulations undertaken with MESO-NH for the IOP 15 event (Hoinka et al., 2003).

Further information on the nature of the orographic and diabatic influences was gleaned from combined measurement and model studies of the IOP 15 event. DIAL measurements showed a modification at the leading edge of the streamer due to convective activity (Hoinka et al., 2003), with large pertubations at the base of the tropopause layer. Observations and numerical model simulations with MESO-NH serve to support the interpretation that convection was generated ahead of the streamer and there might also have been a breaking of buoyancy waves generated above the south-western Alps.

The evolution of the IOP 15 streamer was recorded in an earlier section. Between 00 UTC on 6 and 7 November, the streamer deformed as it approached the Alps and subsequently split to form a cut-off. It was also noted earlier that this cut-off formation is often an integral feature of rapid cyclogenesis resulting in a lee cyclone in the Gulf of Genoa. The accompanying surface synoptic evolution is that of a 'parent' cyclone located over central Europe with its attached cold front moving southeastwards and deforming in an arch around the Alps (Steinacker, 1984). Numerical simulations of the event conducted with and without flattened orography indicate that the cut-off low was essentially orographically induced (Buzzi et al., 2003). Without orography there is no secondary cyclogenesis but a single deeper and broader cyclone migrates from the North Sea towards the Balkans, while an upper-level cut-off develops more slowly and by mid-day of 7 November is located about $5^{\circ}$ east-north-east of the observed position. The inference is that the cut-off was not merely a self development but rather was subject to strong orographic influence. In effect the orography plays a dual role by both inducing the cut-off and anchoring the streamer's movement.

In summary, independent sets of model simulations plus DIAL measurements indicate clearly that
(1) topographic and diabatic effects are significant,

(2) the two effects are of comparable magnitude,

(3) both effects reduce the streamer's PV,

(4) topographic effects are strong at the streamer's tip,

(5) diabatic effects decelerate the streamer's progression,

(6) synergetic effects of both produce PV filaments north of the Alps, and

(7) topographic effects strengthen the streamer's cut-off.

\section{Numerical weather prediction}

QPF is currently one of the most critical operational forecasting challenges. The timing, amplitude and distribution of the precipitation is determined by an amalgam of effects that include the availability and amount of moisture at low levels, the efficacy of the cloud microphysics, orographic influences that encompass both possible blocking of low-level flow and induction of forced ascent, and the nature of the ambient synoptic setting. Likewise the prediction skill will also depend upon how well these factors are adequately captured/represented in the initial state/physics of the forecast model, and moreover the relative contribution of these various factors should influence the strategy for improving QPF.

The hypothesis that prompted the $\mathrm{P} 2$ project of MAP was that the appearance of a synoptic-scale PV streamer upstream of the Alps constitutes a significant dynamical precursor of a mesoscale HP event on the Alpine south side. It is therefore appropriate to query whether

(1) the early detection of such a streamer enhances the predictive capability of an HP event, and

(2) the presence of a streamer is merely an incidental accompanying features or a central (or perhaps even dominant) component of an HP event.

The answer to both queries impacts directly upon the major MAP aim to improve QPF and related flood forecasts.

We address each query in turn. For the first query on the potential enhancement of predictive skill, note that the statistical significance of the composite lagged correlation of the upstream PV pattern from day 1 out to day 6 with the subsequent Alpine HP event (Martius, 2005) provides a clear indication that accurate medium-range prediction of the streamer is potentially achievable. Moreover the composite patterns point to the physical nature of the pre-streamer signal's propagation as a disturbance on the extratropical wave-guide formed by the sharp gradient of PV on tropopause-transecting isentropic surfaces (cf. Schwierz et al., 2004; Shapiro and Thorpe, 2004). Accurate representation of this process requires adequate tropopause-level data, high spatial resolution for the model, and the faithful replication by the model of the generation and maintenance of the atmosphere's strong and localized isentropic PV gradient. The latter point relates to two related issues. First, for the propagation of the pre-streamer disturbance far upstream, 
there is clear evidence (Dirren et al., 2003) that NWP models often underestimate the amplitude of disturbances on the wave-guide. Second, the formation and elongation of the streamer immediately upstream of the Alps has been linked to the intensification of the wave-guide's PV gradient by diabatic production of a band of low PV on the guide's equatorward side (Massacand et al., 2001). This process requires that a forecast model adequately replicates the band's production, and this again is a significant model challenge.

For the second query we note that the derived streamer climatology (see Section 3) indicates that with relatively high probability certain PV streamer configurations (differing slightly from one another) are associated with heavy precipitation in different sub-regions of the Alps. This suggests in turn that the accurate prediction of a streamer's orientation, movement and amplitude has implications for the mesoscale QPF distribution. This has been borne out by the results of two separate studies (Fehlmann et al., 2000; Fehlmann and Quadri, 2000). The first study demonstrated that a good representation of distinctive mesoscale PV sub-structures within a streamer, and in particular in the vicinity of the streamer's tip, had a significant impact upon the location of the precipitation for an individual HP event. The second study, involving multi-day predictions with a mesoscale NWP system, provided corroborative evidence in that it documented that (un)successful HP forecasts for the Alpine south side were preceded and accompanied by (in)accurate representation of the location and amplitude of the southern part of the streamer's PV distribution. Thus there is persuasive evidence that a streamer's internal mesoscale structure and overall synoptic-scale representation does impact upon the resulting forecast of the precipitation.

It is difficult to assess and quantify the relative importance of the streamer in comparison with other predominantly lower-tropospheric mesoscale effects. The studies discussed above differ in concept and intent from the examination of the capability of operational and research mesoscale models to replicate individual HP events - e.g. the papers in the special issues of MAP (Bougeault et al., 2003) and HERA (Volkert, 2000), and also Benoit et al., (2002). In these studies the focus was on the microand mesoscale evolution of the precipitation, and the characteristics of orographically influenced precipitation. However one heuristic mesoscale model study (Gheusi and Davies, 2004) showed that a bland incident flow was still capable of reproducing the climatological precipitation pattern with its mesoscale sub-structure. This leaves open the possibility that the combination of the ambient synoptic setting allied with the role of orography plays a decisive key in generating the HP events.

\section{Final remarks}

The overall goal of the MAP project 'Incident uppertropospheric PV anomalies' was to elucidate the linkage between PV streamers and Alpine weather and airflow.
Here we summarize the progress made toward achieving this project's specific objectives.

(1) A synoptic climatology was derived of European PV streamers based on the ERA-40 dataset. It shows a strong linkage between streamers and Alpine events of heavy precipitation. For the period 1966-1999, $73 \%$ of extreme heavy precipitation events $\left(\geq 29 \mathrm{~mm} \mathrm{~d}^{-1}\right)$ on the southern side of the Alps are accompanied by a PV streamer present at the western edge of the Alps. Lagged correlation of PV pattern of the ERA-40 fields with the time series of ECMWF forecast precipitation produces the archetypical signal of an upstream-located elongated streamer.

(2) The DLR water vapour lidar system (DIAL), a key instrument for the field programme, enabled crosssections of the humidity field to be compiled within the dry stratospheric air of the streamer air, and they were compared with quasi-contemporaneous analyses and mesoscale simulations fields. These complementary fields showed a satisfactory measure of agreement for the overall stucture.

(3) The DIAL data also detected distinctive substructures on the lower boundary of, and within, the streamer. Credence for these sub-structures was evinced using appropriately designed numerical simulations and by deploying backward-trajectory techniques. The resulting enhanced fields shed light on the temporal coherence and 3D form of the substructures.

(4) Numerical simulations helped to pinpoint the nature and impact of the Alps upon streamer development. Topographic and cloud-diabatic effects were shown to be comparable in amplitude, and they were significant in reducing the streamer's PV, streamlining its shape, and modifying its movement. In combination they were shown to be capable of inducing a cut-off at the streamer's southern tip.

(5) Evidence was provided that accurate representation of a streamer's far-upstream evolution could enhance the medium-term predictive capability for HP events, and that a good representation of the streamer's location and major internal structures as it approached the Alps might (at least on occasions) be a prerequisite for accurate shorter-term deterministic QPF.

Further, we note that the operation of the newly developed DIAL system during the MAP field phase was an excellent opportunity to assess its capabilities, and it thereby provides the basis for its further development. Subsequently the instrument has been deployed in various experiments worldwide collecting data in a quasioperational mode. Moreover in the ESA explorer mission Water vapour Lidar Experiment in Space (WALES), it is planned to develop a spaceborne DIAL to provide global coverage of humidity profile data. Hence MAP has proved to be a major spur for this further technical evolution. 
The streamer project of MAP encompassed a wide range of spatial scales, from the synoptic-scale environment in which the streamer is embedded to the finer-scale cloud processes, and the experience gained in the programme has some general value for the execution of future experiments. Limitations on aircraft deployment due to air traffic control, aircraft ceiling and endurance, and the installation of the measurements system all contributed to limiting the field campaign activities, and prohibited the acquisition of a fully 3D picture of the streamer. Notwithstanding, the aircraft missions do provide valuable measurements for validating mesoscale model simulations. A bonus for the design of the missions was that the 24-hour ECMWF forecasts provided excellent guidance. The forecast utility for predicting the streamer's location and lateral boundaries at longer lead times was event dependent and hence more problematic.

In summary, the project on 'Incident upper-tropospheric PV anomalies' attained most of its major goals, and increased our knowledge of the dynamics, significance, and internal structure of PV streamers. It has served both to prompt and provide a basis for further research studies and forecast activities. At the very least, it has helped engender a fresh focus on the necessity to account adequately for upper-level effects in the process of data acquisition and NWP, and to highlight a range of intriguing dynamical issues associated with the dynamics of PV streamers.

\section{Acknowledgements}

The MAP project P2 could not have been undertaken without the assistance and support of a large number of individuals with a wide range of skills. We express our gratitude to our colleagues from DLR Oberpfaffenhofen (Hans Schlager for providing POLINAT data; Andreas Fix, Christoph Kiemle, and Gorazd Poberaj for enthusiastically measuring and elaborating the DIAL data; Winfried Beer for assistance with processing of graphics and text), to our colleagues at the ETH Zürich (Conny Schwierz and Olivia Martius for insightful input), and to Günther Zängl (MIM, Universität München) for performing the numerical simulation of the IOP 17 event. The operational ECMWF data were kindly provided by the Centre within the special project entitled 'The climatology of the global tropopause'. Finally we wish to thank the two anonymous reviewers for contributions that helped to improve the clarity of the text.

\section{References}

Appenzeller C, Davies HC. 1992. Structure of stratospheric intrusions into the troposphere. Nature 358: 570-572.

Benoit R, Schär C, Binder P, Chamberland S, Davies HC, Desgagné M, Girard C, Keil C, Kouwen N, Lüthi D, Maric D, Müller E, Pellerin P, Schmidli J, Schubiger F, Schwierz C, Sprenger M, Walser A, Willemse S, Yu W, Zala E. 2002. The real-time ultrafinescale forecast support during the Special Observing Period of the MAP. Bull. Am. Meteorol. Soc. 83: 85-109.

Bougeault P, Binder P, Buzzi A, Dirks R, Houze R, Kuettner JP, Smith RB, Steinacker R, Volkert H. 2001. The MAP Special Observing Period. Bull. Am. Meteorol. Soc. 82: 433-462.
Bougeault P, Houze RA, Rotunno R, Volkert H. (Eds.) 2003. Special issue of MAP. Q. J. R. Meteorol. Soc. 129: 341-899.

Browell EV, Danielsen EF, Ismail S, Gregory GL, Beck SM. 1987. Tropopause fold structure determined from airborne lidar and in situ measurements. J. Geophys. Res. 92: 2112-2120.

Buzzi A, d'Isidoro M, Davolio S. 2003. A case-study of an orographic cyclone south of the Alps during MAP SOP. Q. J. R. Meteorol. Soc. 129: $1795-1818$.

Caccia J-L, Aubagnac J-P, Bethenod G, Bourdier C, Bruzzese E, Campistron B, Candusso J-P, Cherel G, Claeyman J-P, Conrad J-L. 2001. The French ST-radar network during MAP: Observational and scientific aspects. Meteorol. Z. 10: 469-478.

Danielsen EF, Hipskind RS, Gaines SE. 1987. Three-dimensional analysis of potential vorticity associated with tropopause folds and observed variations of ozone and carbon monoxide. J. Geophys. Res. 92: $2103-2111$.

D’Aulerio P, Fierli F, Congeduti F, Redaelli G. 2005. Analysis of water vapour LIDAR measurements during the MAP campaign: Evidence of sub-structures of stratospheric intrusions. Atmos. Chem. Phys. 5: $1301-1310$.

Dirren S, Didone M, Davies HC. 2003. Diagnosis of 'Forecast-Analysis' difference of a weather prediction system. Geophys. Res. Lett. 30: 2060. doi:10.1029/2003GL017986.

Ehret G, Kiemle C, Renger W, Simmet G. 1993. Airborne remote sensing of tropospheric water vapour with a near-infrared differential absorption lidar system. Appl. Optics 32: 4534-4551.

Ehret G, Hoinka KP, Stein J, Fix A, Kiemle C, Poberaj G. 1999. Low stratospheric water vapour measured by an airborne DIAL. $J$. Geophys. Res. 104: 31351-31359.

Fehlmann R. 1997. 'Dynamics of seminal PV elements'. Doctoral dissertation (ETH No. 12229), ETH Zürich, Switzerland.

Fehlmann R, Quadri C. 2000. Predictability issues of heavy Alpine south-side precipitation. Meteorol. Atmos. Phys. 72: 223-231.

Fehlmann R, Quadri C, Davies HC. 1999. An Alpine rainstorm: Sensitivity to the mesoscale upper-level structure. Weather and Forecasting 15: 4-28.

Frei C, Schär C. 1998. A precipitation climatology of the Alps from high-resolution rain-gauge observations. Int. J. Climatol. 18: 873-900.

Gheusi F, Davies HC. 2004. Autumnal precipitation distribution on the southern flank of the Alps: A numerical model study of the mechanisms. Q. J. R. Meteorol. Soc. 130: 2125-2152.

Griffiths M, Thorpe AJ, Browning KA. 2000. Convective destabilization by a tropopause fold diagnosed using potential-vorticity inversion. Q. J. R. Meteorol. Soc. 126: 125-144.

Guenard V, Dobrinski P, Caccia J-L, Campistron B, Benech B. 2005. An observational study of the mesoscale mistral dynamics. Boundary-Layer Meteorol. 115: 263-288.

Hoinka KP, Zängl G. 2004. The influence of the vertical coordinate system on simulations of a PV streamer crossing the Alps. Mon. Weather Rev. 132: 1860-1867.

Hoinka KP, Richard E, Poberaj G, Busen R, Caccia JL, Fix A, Mannstein H. 2003. Analysis of a potential vorticity streamer crossing the Alps during MAP IOP 15 on 6 November 1999. Q. J. R. Meteorol. Soc. 129: 609-632.

Hoinka KP, Schwierz C, Martius O. 2006. Synoptic-scale weather patterns during Alpine heavy rain events. Q. J. R. Meteorol. Soc. 132: $2853-2860$.

Holopainen EO, Rontu L. 1981. On shear lines in the upper troposphere over Europe. Tellus 33: 351-359.

Juckes M, Smith RK. 2000. Convective destabilization by upper-level troughs. Q. J. R. Meteorol. Soc. 126: 111-123.

Keil C, Cardinali C. 2004. The ECMWF reanalysis of the MAP Special Observing Period. Q. J. R. Meteorol. Soc. 130: 2827-2849.

Krichak SO, Alper P, Dayan M. 2004. The role of atmospheric processes associated with hurricane Olga in the December 2001 floods in Israel. J. Hydrometeorol. 5: 1259-1270.

Kuettner JP. 1986. The aim and the conduct of ALPEX. Pp 3-14 in Scientific results of the Alpine experiment. GARP Publication Series No.27, WMO/TD 108, World Meteorol. Organization: Geneva.

Liniger MA, Davies HC. 2003. Sub-structure of a MAP streamer. $Q$. J. R. Meteorol. Soc. 129: 633-651.

Maddox RA, Chappell CF, Hoxit LR. 1979. Synoptic and meso-alpha scale aspects of flash flood events. Bull. Am. Meteorol. Soc. 60: $115-123$.

Martius O. 2005. 'Climatological aspects of wave disturbances on the tropopause and links to extreme weather in Europe'. Doctoral thesis (No. 16151), ETH Zürich, Switzerland. 
Martius O, Zenklusen E, Schwierz C, Davies HC. 2006. Episodes of Alpine heavy precipitation with an overlying elongated stratospheric intrusion: A climatology. Int. J. Climatol. 26: 1149-1164.

Massacand AC, Wernli H, Davies HC. 1998. Heavy precipitation on the Alpine southside: An upper-level precursor. Geophys. Res. Lett. 25: $1435-1438$.

Massacand AC, Wernli H, Davies HC. 2001. Influence of upstream diabatic heating upon an Alpine event with heavy precipitation. An upper-level precursor. Mon. Weather Rev. 129: 2822-2828.

Morgenstern O, Davies HC. 1999. Disruption of an upper-lever PVstreamer by orography and cloud-diabatic effects. Contrib. Atmos. Phys. 72: 173-186.

Poberaj G, Fix A, Assion A, Wirth M, Kiemle C, Ehret G. 2002. Airborne all-solid-state DIAL for water vapour measurements in the tropopause region: System description and assessment of accuracy. Appl. Phys. B 75: 165-172.

Price JD, Vaughan G. 1992. Statistical studies of cut-off low systems. Ann. Geophysicae 10: 96-102.

Schär C, Leuenberger D, Fuhrer O, Lüthi D, Girard C. 2002. A new terrain-following vertical coordinate formulation for atmospheric prediction models. Mon. Weather Rev. 130: 2459-2480.

Schumann U, Schlager H, Arnold F, Ovarlez J, Kelder H, Hov O, Hayman G, Isaksen ISA, Staehelin J, Whitefield PD. 2000. Pollution from aircraft emissions in the North Atlantic flight corridor: Overview on the POLINAT project. J. Geophys. Res. 105(D3): 3605-3631.

Schwierz C, Dirren S, Davies HC. 2004. Forced waves on a zonally aligned jet stream. J. Atmos. Sci. 61: 73-87.

Shapiro MA, Thorpe AJ. 2004. THORPEX International Science Plan (Version 3). WMO/TD-No. 1246, WWRP/THORPEX No.2, World Meteorol. Organization: Geneva; available on http://www.wmo.int/pages/prog/arep/thorpex/pdf/CD_ROM_inter national_science_plan_v3.pdf.

Smith W, Younkin RJ. 1972. An operationally useful relationship between the polar jet stream and heavy precipitation. Mon. Weather Rev. 100: 434-440.
Steinacker R. 1984. Airmass and frontal movement around the Alps. Riv. Meteorol. Aeronaut. 44: 85-93.

Steinacker R. 2000. 'The MAP-SOP MAN'. MAP Newsletter 12: 2-4. MeteoSwiss: Zürich, Switzerland; available on http://www.map.meteoswiss.ch/map-doc/newsletter.htm.

Sutcliffe RC, Forsdyke AG. 1950. The theory and use of upper air thickness patterns for forecasting. Q. J. R. Meteorol. Soc. 76: 189-217.

Sutton RT, Maclean H, Swinbank R, O’Neill A, Taylor FW. 1994. High resolution stratospheric tracer fields estimated from satellite observations using Lagrangian trajectory calculations. J. Atmos. Sci. 51: 2995-3005.

Thomas W, Baier F, Erbertseder T, Kästner M. 2003. Analysis of the Algerian severe weather event in November 2001 and its impact on ozone and nitrogen dioxide distribution. Tellus 55B: 993-1006.

Tripoli GJ, Medaglia CM, Dietrich S, Mugnai A, Panegrossi G, Pinore S, Smith EA. 2005. The 9-10 November 2001 Algerian flood. Bull. Am. Meteorol. Soc. 86: 1229-1235.

Uppala SM, Kallberg PW, Simmons AJ, Andrae U, da Costa Bechtold V, Fiorino M, Gibson JK, Haseler J, Hernandez A, Kelly GA, Li X, Onogi K, Saarinen S, Sokka N, Allan RP, Andersson E, Arpe K, Balmaseda MA, Beljaars ACM, van de Berg L, Bidlot J, Bormann N, Caires S, Chevallier F, Dethof A, Dragosavac M, Fisher M, Fuentes M, Hagemann S, Hólm E, Hoskins BJ, Isaksen L, Janssen PAEM, Jenne R, McNally AP, Mahfouf J-F, Morcrette J-J, Rayner NA, Saunders RW, Simon P, Sterl A, Trenberth KE, Untch A, Vasiljevic D, Viterbo P, Woollen J. 2005. The ERA-40 re-analysis. Q. J. $R$. Meteorol. Soc. 131: 2961-3012.

Volkert H. (Ed.) 2000. Heavy precipitation in the Alpine region (HERA). Meteorol. Atmos. Phys. 72: 71-270.

Volkert H, Gutermann T. 2007. Inter-domain cooperation for mesoscale atmospheric laboratories: The Mesoscale Alpine Programme as a rich study case. Q.J.R. Meteorol. Soc. 133: 949-967. 